\title{
Endocrine-Based Treatments in Clinically-Relevant Subgroups of Hormone Receptor-Positive/HER2-Negative Metastatic Breast Cancer: Systematic Review and Meta-Analysis
}

\author{
Francesco Schettini ${ }^{1,2,3, *}{ }^{\oplus}$, Mario Giuliano ${ }^{1}$, Fabiola Giudici ${ }^{4}{ }^{\oplus}$, Benedetta Conte ${ }^{2,5}$, Pietro De Placido ${ }^{1}$, \\ Sergio Venturini ${ }^{6,7}$, Carla Rognoni ${ }^{7}{ }^{(1)}$, Angelo Di Leo ${ }^{8}$, Mariavittoria Locci ${ }^{9}$, Guy Jerusalem ${ }^{10}$,

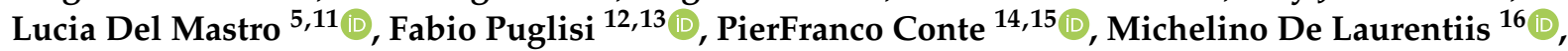 \\ Lajos Pusztai ${ }^{17} \bigodot^{\circ}$, Mothaffar F. Rimawi ${ }^{18,19}{ }^{2}$, Rachel Schiff ${ }^{18,19,20}$, Grazia Arpino ${ }^{1}$, Sabino De Placido ${ }^{1}$, \\ Aleix Prat ${ }^{2,3,21}$ and Daniele Generali ${ }^{22,23, * \mathbb{C}}$
}

check for

updates

Citation: Schettini, F.; Giuliano, M.; Giudici, F.; Conte, B.; De Placido, P.; Venturini, S.; Rognoni, C.; Di Leo, A.; Locci, M.; Jerusalem, G.; et al. Endocrine-Based Treatments in Clinically-Relevant Subgroups of Hormone Receptor-Positive/HER2 Negative Metastatic Breast Cancer: Systematic Review and MetaAnalysis. Cancers 2021, 13, 1458. https://doi.org/10.3390/cancers 13061458

\section{Academic Editors: Francesca}

Pentimalli, Antonio Giordano, Paola Indovina and Rupert Bartsch

Received: 9 February 2021

Accepted: 17 March 2021

Published: 22 March 2021

Publisher's Note: MDPI stays neutral with regard to jurisdictional claims in published maps and institutional affiliations.

Copyright: (C) 2021 by the authors Licensee MDPI, Basel, Switzerland. This article is an open access article distributed under the terms and conditions of the Creative Commons Attribution (CC BY) license (https:/ / creativecommons.org/licenses/by/ $4.0 /)$.
1 Department of Clinical Medicine and Surgery, University of Naples "Federico II", 80131 Naples, Italy; m.giuliano@unina.it (M.G.); pietrodep91@gmail.com (P.D.P.); grazia.arpino@unina.it (G.A.); deplacid@unina.it (S.D.P.)

2 Translational Genomics and Targeted Therapies in Solid Tumors, IDIBAPS, 08036 Barcelona, Spain; bntconte@gmail.com (B.C.); alprat@clinic.cat (A.P.)

3 SOLTI Breast Cancer Research Group, 08008 Barcelona, Spain

4 Unit of Biostatistics, Department of Cardiac, Thoracic, Vascular Sciences and Public Health, University of Padova, 35122 Padova, Italy; fgiudici@units.it

5 Breast Unit, IRCCS Ospedale Policlinico San Martino, 16132 Genoa, Italy; lucia.delmastro@hsanmartino.it

6 Department of Management, University of Turin, 10124 Turin, Italy; sergio.venturini@unibocconi.it

7 Centre for Research on Health and Social Care Management (CERGAS), SDA Bocconi School of Management, 20136 Milan, Italy; carla.rognoni@unibocconi.it

8 "Sandro Pitigliani" Medical Oncology Department, Hospital of Prato, 59100 Prato, Italy; angelo.dileo@uslcentro.toscana.it

9 Department of Neuroscience, Reproductive Medicine and Odontostomatological Sciences, University of Naples Federico II, 80131 Naples, Italy; mariavittorialocci@virgilio.it

10 Medical Oncology Department, Centre Hospitalier Universitaire de Liège and Liège University, 4000 Liège, Belgium; g.jerusalem@chu.ulg.ac.be

11 Department of Internal Medicine and Medical Specialties (DIMI), School of Medicine, University of Genoa, 16132 Genoa, Italy

12 Department of Medicine, University of Udine, 33100 Udine, Italy; fabio.puglisi@uniud.it

13 IRCCS Centro di Riferimento Oncologico Aviano, National Cancer Institute, 33081 Aviano, Italy

14 Department of Surgery, Oncology and Gastroenterology, University of Padova, 35122 Padova, Italy; pierfranco.conte@unipd.it

15 Division of Medical Oncology 2, Istituto Oncologico Veneto-IRCCSS, 35128 Padova, Italy

16 Breast Oncology Unit, INT-Fondazione "G. Pascale", 80131 Naples, Italy; m.delaurentiis@istitutotumori.na.it

17 Department of Medicine, Yale University School of Medicine, New Haven, CT 06510, USA; lajos.pusztai@yale.edu

18 Dan L Duncan Comprehensive Cancer Center, Baylor College of Medicine, Houston, TX 77030, USA; rimawi@bcm.edu (M.F.R.); rschiff@bcm.edu (R.S.)

19 Department of Medicine, Baylor College of Medicine, Houston, TX 77030, USA

20 Department of Molecular and Cellular Biology, Baylor College of Medicine, Houston, TX 77030, USA

21 Department of Medical Oncology, Hospital Clínic, 08036 Barcelona, Spain

22 Department of Medical, Surgery and Health Sciences, University of Trieste, 34127 Trieste, Italy

23 Breast Cancer Unit, Azienda Socio Sanitaria Territoriale di Cremona, 26100 Cremona, Italy

* Correspondence: schettini@clinic.cat (F.S.); dgenerali@units.it (D.G.); Tel.: +34-93-402-0408 (F.S.); +39-(0)-372-408-042 (D.G.)

Simple Summary: Hormone receptor-positive $(\mathrm{HR}+)$ /HER2-negative is the most frequent subgroup of metastatic breast cancer (MBC). Important therapeutic advances in the treatment of this tumor type have been observed in the last 20 years, with the approval of numerous endocrine therapies (ET) with or without target therapies (TT). To improve our current knowledge and support clinical decision-making, we conducted a systematic literature and meta-analysis focused on the most relevant/promising first-/second-line ET \pm TT of the last 20 years. We observed that CDK4/6inhibitors(i) + ET were the most effective regimens. At the same time, mTORi-based combinations 
proved to be a valid therapeutic option in endocrine-resistant tumors, as well as PI3Ki + ET in PIK3CA-mutant patients. Single agent ET might still be a valuable upfront treatment in endocrine sensitive and non-visceral disease.

Abstract: A precise assessment of the efficacy of first-/second-line endocrine therapies (ET) \pm target therapies (TT) in clinically-relevant subgroups of hormone receptor-positive (HR+)/HER2-negative metastatic breast cancer (MBC) has not yet been conducted. To improve our current knowledge and support clinical decision-making, we thus conducted a systematic literature search to identify all first/second-line phase II/III randomized clinical trials (RCT) of currently approved or most promising $\mathrm{ET} \pm \mathrm{TT}$. Then, we performed a meta-analysis to assess progression-free (PFS) and/or overall survival (OS) benefit in several clinically-relevant prespecified subgroups. Thirty-five RCT were included (17,595 patients). Pooled results show significant reductions in the risk of relapse or death of $26-41 \%$ and $12-27 \%$, respectively, depending on the clinical subgroup. Combination strategies proved to be more effective than single-agent ET (PFS hazard ratio (HR) range for combinations: 0.60-0.65 vs. HR range for single agent ET: 0.59-1.37; OS HR range for combinations: $0.74-0.87$ vs. HR range for single agent ET: 0.68-0.98), with CDK4/6-inhibitors(i) + ET being the most effective regimen. Single agent ET showed comparable efficacy with ET+TT combinations in non-visceral $(p=0.63)$ and endocrine sensitive disease $(p=0.79)$, while mTORi-based combinations proved to be a valid therapeutic option in endocrine-resistant tumors, as well as PI3Ki + ET in PIK3CA-mutant tumors. These results strengthen international treatment guidelines and can aid therapeutic decision-making.

Keywords: endocrine therapy; hormone receptor; metastatic breast cancer; meta-analysis; systematic review

\section{Introduction}

About $60-75 \%$ of breast tumors are hormone receptor-positive $(\mathrm{HR}+)$ and do not present with HER2 overexpression or amplification (HER2-) [1]. Following the introduction of multiple novel therapeutic agents into clinical practice, HR+/HER2- metastatic breast cancer (MBC) has become a more chronic and manageable disease, albeit still incurable [2-13]. Indeed, death rates decreased by an average of $1.8 \%$ annually between 2007 and 2016 [14], and a recent meta-analysis reported a median survival increase from 32 months in 1990 (95\% confidence interval (CI): 23-43) to 57 (95\% CI: 37-87) months [15]. Current international guidelines recommend treating HR+/HER2- MBC by administering endocrine treatment (ET), combined or not with TT, for as long as possible before changing to chemotherapy, except in the case of "visceral crisis" [16-18]. In fact, we previously demonstrated the absence of significant difference between ET + TT and chemotherapy and the clear superiority of ET combined with novel CDK4/6-inhibitors (CDK4/6i) or $\mathrm{PIK} 3 \mathrm{CA} / \mathrm{mTOR}$ axis inhibitors compared to standard ET, in terms of both response rates and progression-free survival (PFS) [19]. However, previous network meta-analyses comparing all first-/second-line treatment options [19-22] were unable to evaluate the efficacy of these novel treatment strategies in specific clinical subsets (endocrine-resistant or endocrine-sensitive patients, patients with visceral or bone-only disease, pre-menopausal patients, etc.) and did not provide overall survival (OS) data. Therefore, to support current treatment guidelines and aid therapeutic decision-making in more specific tumor subsets, we performed a meta-analysis with preplanned subgroup analyses and meta-regression to evaluate the benefit of all currently available and most promising first-/second-line ET-based treatments in clinically relevant subgroups of HR+/HER2- MBC.

\section{Materials and Methods}

\subsection{Search Strategy and Selection Criteria}

After a systematic review of the literature [19] (details in the Text S1), we selected all phase II/III RCT published between January 2000 and December 2019 that compared the ef- 
fect of ET and/or ET combined with the most relevant TT in the first-/ second-line treatment of HR+/HER2 - MBC. The following TT were selected: CDK4/6-inhibitors (palbociclib, ribociclib and abemaciclib), mTOR-inhibitors (mTORi; everolimus and temsirolimus), PI3Kinhibitors (PI3Ki; buparlisib, pictilisib and alpelisib), AKT-inhibitors (AKTi; capivasertib) and histone deacetylase inhibitors (HDACi; entinostat). These drugs were selected because they: (i) were already approved (CDK4/6i, everolimus and alpelisib); or (ii) had shown promising results in phase II trials and were under further investigation at the time of the literature review (capivasertib and entinostat); or (iii) were of the same molecular class as the approved TT included in our study (everolimus and alpelisib) but were not approved because of drug-specific limitations (temsirolimus, pictilisib and buparlisib). As ET, we evaluated only currently approved drugs, namely tamoxifen, aromatase inhibitors (AI; anastrozole, letrozole and exemestane), progestins (megestrol acetate) and fulvestrant.

\subsection{Data Extraction}

Details of the study design, patient characteristics, current and previous treatment were extracted from each paper, together with hazard ratios and associated $95 \%$ confidence intervals for PFS, time-to-progression (TTP) and OS, when reported. These data had to be publicly available or computable from published paper/abstracts, otherwise studies were excluded. TTP was considered when PFS was not available, as reported elsewhere [19,21].

\subsection{Study Endpoints}

The primary endpoint was the pooled PFS/TTP and the secondary endpoint was the pooled OS estimated in prespecified clinically relevant subgroups of HR+/HER2- MBC when comparing all new ET, ET + TT or ET combinations versus the previous standard ET. We then used subgroup analysis and meta-regression to explore the effect on PFS/TTP and OS of the different treatment strategies and drug classes considered in prespecified clinically-relevant subgroups. The subgroups were the following: visceral, non-visceral and bone-only disease, PIK3CA-mutant/non-mutant tumors, endocrine-sensitive/-resistant tumors, primary and secondary endocrine-resistance and pre/peri- and postmenopause. Endocrine sensitivity status was defined according to ESO-ESMO breast cancer treatment guidelines (Text S1) [18]. All patients enrolled in RCT that investigated metastatic endocrine treatment lines after the first-line were considered to be affected by endocrine resistance. A distinction between primary or secondary resistance was not always feasible. We specifically selected the above-mentioned subgroups because we believed they were at the same time: (1) useful in the daily clinical practice; and (2) mostly retrievable from published RCT, or at least part of them.

\subsection{Data Analysis}

We generated pooled HRs using the inverse-variance weighting method. As we expected heterogeneity among studies, we selected a priori the DerSimonian and Laird random effect model [23]. Pooled data are reported in forest plots. Statistical significance was set at $p<0.05$. All tests were two-sided. Inter-study heterogeneity was assessed by visual inspection of the forest plots and the $\mathrm{I}^{2}$ statistic [24]. We assessed publication bias and small study effects with funnel plots and the Egger's test [25]. Subgroup analyses were performed if at least 3 studies comparing 2 different combinations of therapy or 2 different drug classes were available. Meta-regression was performed when at least 10 studies were available. Statistical analyses were performed using R software (R Foundation for Statistical Computing, Vienna, Austria) version 3.5.0, package meta (https:/ / www.r-project.org (accessed on May 2018)). The risk of bias for each trial was assessed according to the criteria outlined in the Cochrane Handbook for Systematic Reviews of Interventions (available at: https: / training.cochrane.org/cochrane-handbooksystematic-reviews-interventions\#how-to-access (accessed on July 2019)). Internal validity of eligible studies was assessed according to the Cochrane Collaboration's Risk of Bias tool 
in Review Manager (software available at: https:/ / training.cochrane.org/online-learning/ core-software-cochrane-reviews/revman/reasons-downloading-revman-5 (accessed on February 2019)). The project is registered in the Open Science Framework online repository (https:// osf.io; doi: 10.17605/OSF.IO/79D4U, accessed on January 2020).

\section{Results}

\subsection{Study Characteristics}

Based on these criteria, we identified 35 randomized controlled trials (RCT) for a total of 17,595 patients [3-10,26-52]. Details of the study selection are reported in the PRISMA diagram (Figure 1).

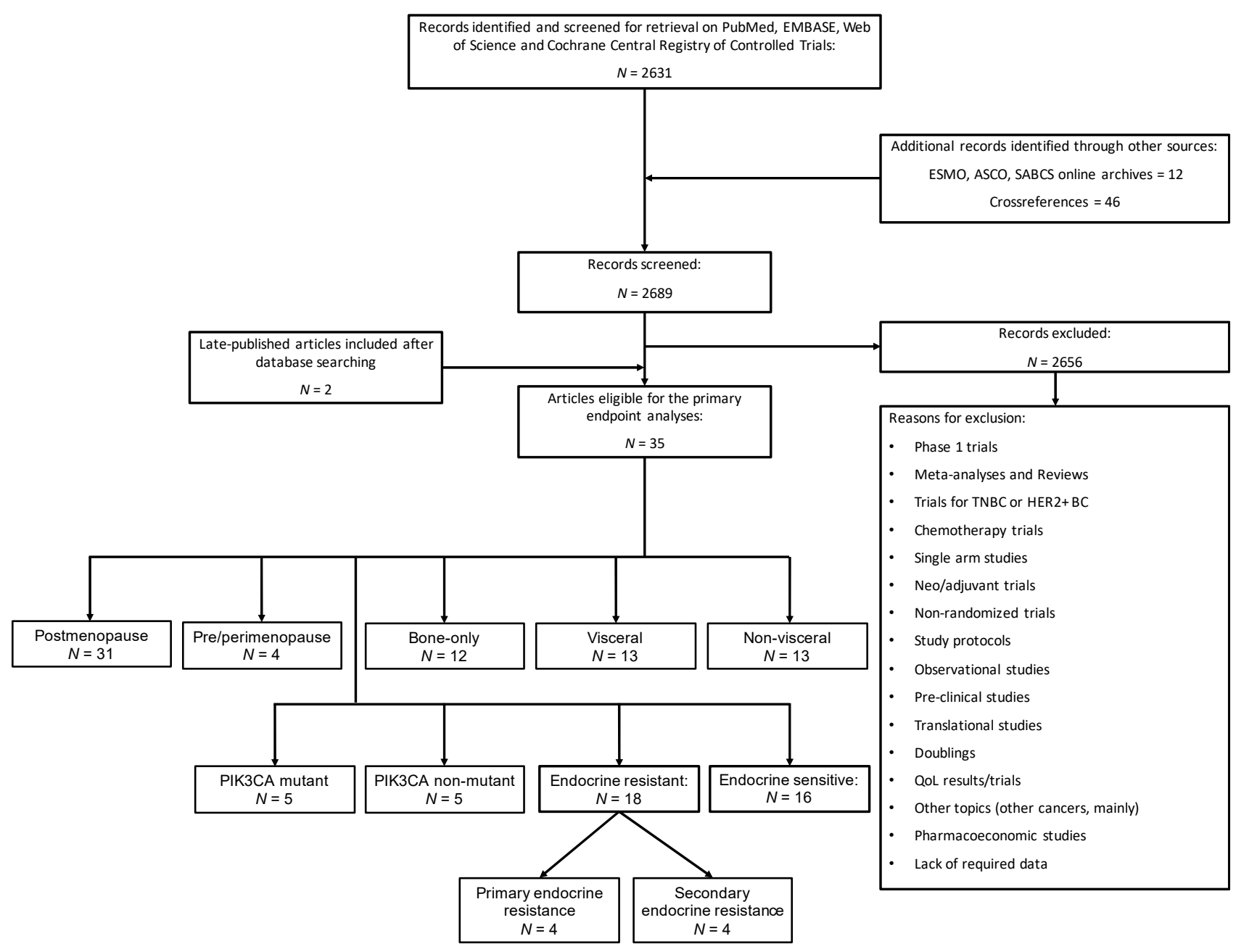

Figure 1. PRISMA diagram.

The median follow-up for the studies included was 18.8 (interquartile range (IQR): 13.0-24.2, min-max range: 4.2-87.6) months, all 35 studies were multicenter, 27 (77.1\%) were phase III trials, 7 (20.0\%) were phase II and $1(2.9 \%)$ was a phase II/III trial. Sixteen studies $(45.7 \%)$ included only the first-line setting, eighteen $(51.4 \%)$ enrolled patients in first-line or more advanced and one trial was set in second-line or more $(2.9 \%)$. Two $(5.7 \%)$ studies enrolled only premenopausal patients, two (5.7\%) enrolled pre- and postmenopausal patients, and thirty-one (88.6\%) only enrolled postmenopausal patients. Study characteristics are detailed in Table S1. The studies were further regrouped according to treatment strategy (studies of combination treatments (ET + TT or ET combinations) compared to single agent ET vs. studies of single agent ET) and drug class (studies evaluating CDK4/6i-, mTORi-, PI3Ki-, HDCAi- and AKTi-based combinations with ET vs. single 
agent ET; SERD (only fulvestrant) vs. AI or SERM (only tamoxifen); SERD + AI vs. SERD; SERD + AI vs. AI and AI vs. tamoxifen).

\subsection{Pooled Estimates in Clinical Subsets}

New ET, ET + TT and ET combinations developed in the last two decades significantly improved PFS compared to the previous standard ET (Hazard Ratio (HR) range: 0.59-0.78, $p$-value range: $<0.001-0.042$; $\mathrm{I}^{2}$ range: $0.00-86.20 \%$, pheterogeneity $\left(\mathrm{p}_{\mathrm{H}}\right)$ range: $\left.<0.001-0.75\right)$ (Figure 2A,C, Figure 3A,C,E, Figure 4A,C,E,F and Figure 5A,B). Heterogeneity was high in the endocrine-sensitive/resistant and postmenopausal subgroups $\left(\mathrm{I}^{2}: 85.4 \%, 82.10 \%\right.$ and $86.2 \%$, respectively; $\mathrm{p}_{\mathrm{H}}<0.001$ for all).

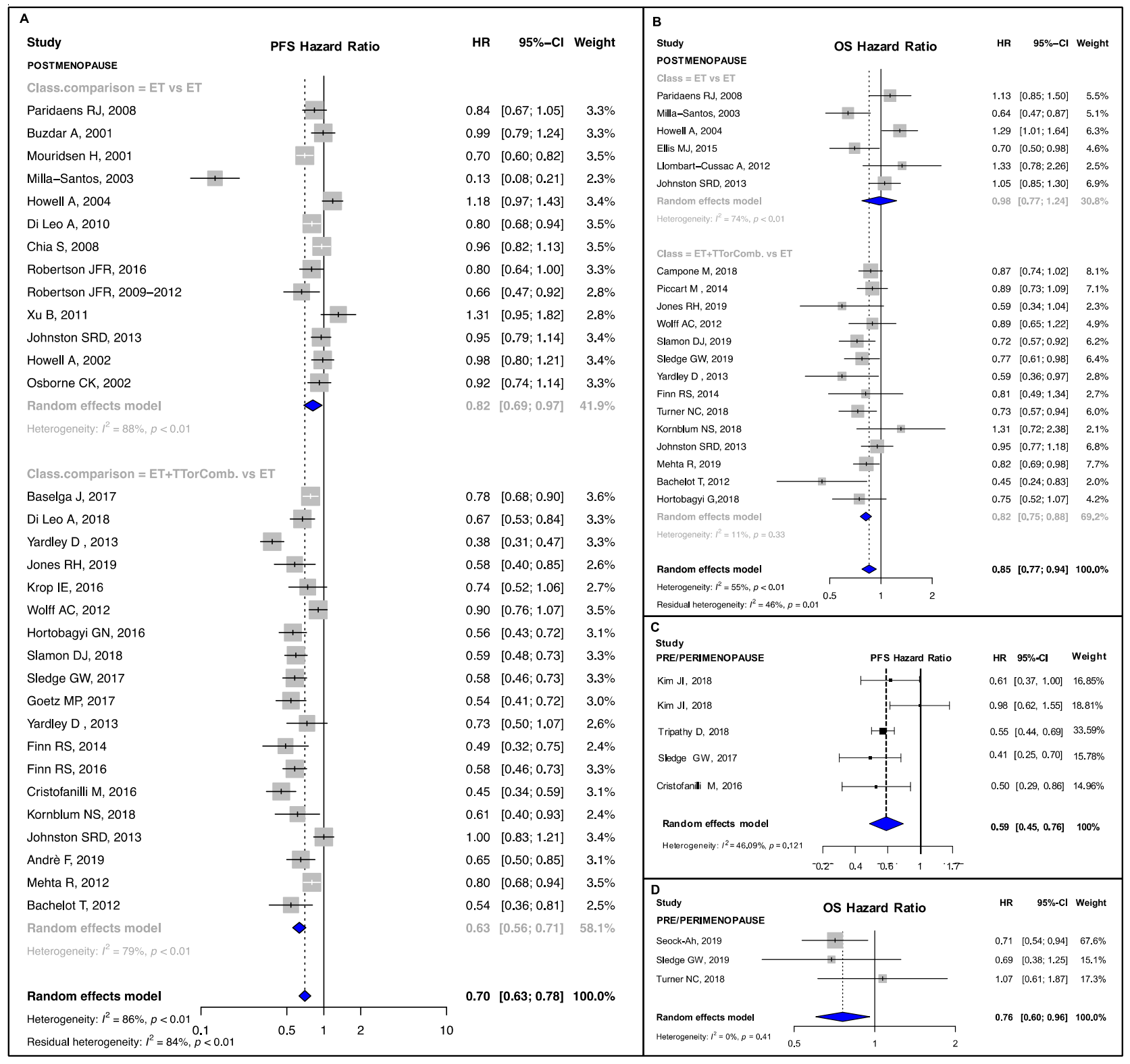

Figure 2. PFS and OS pooled results according to menopausal status: PFS (A) and OS (B) pooled result for the postmenopausal subgroup, overall and according to treatment strategy; and PFS (C) and OS (D) pooled result for the pre/perimenopausal subgroup. PFS, progression-free survival; OS, overall survival; ET vs. ET, studies comparing single endocrine agents therapies; ET + TTorComb. vs. ET, studies comparing endocrine therapies + target therapies or endocrine therapies combinations against single agent endocrine treatments; HR, hazard ratio; 95\% CI, 95\% confidence interval. 


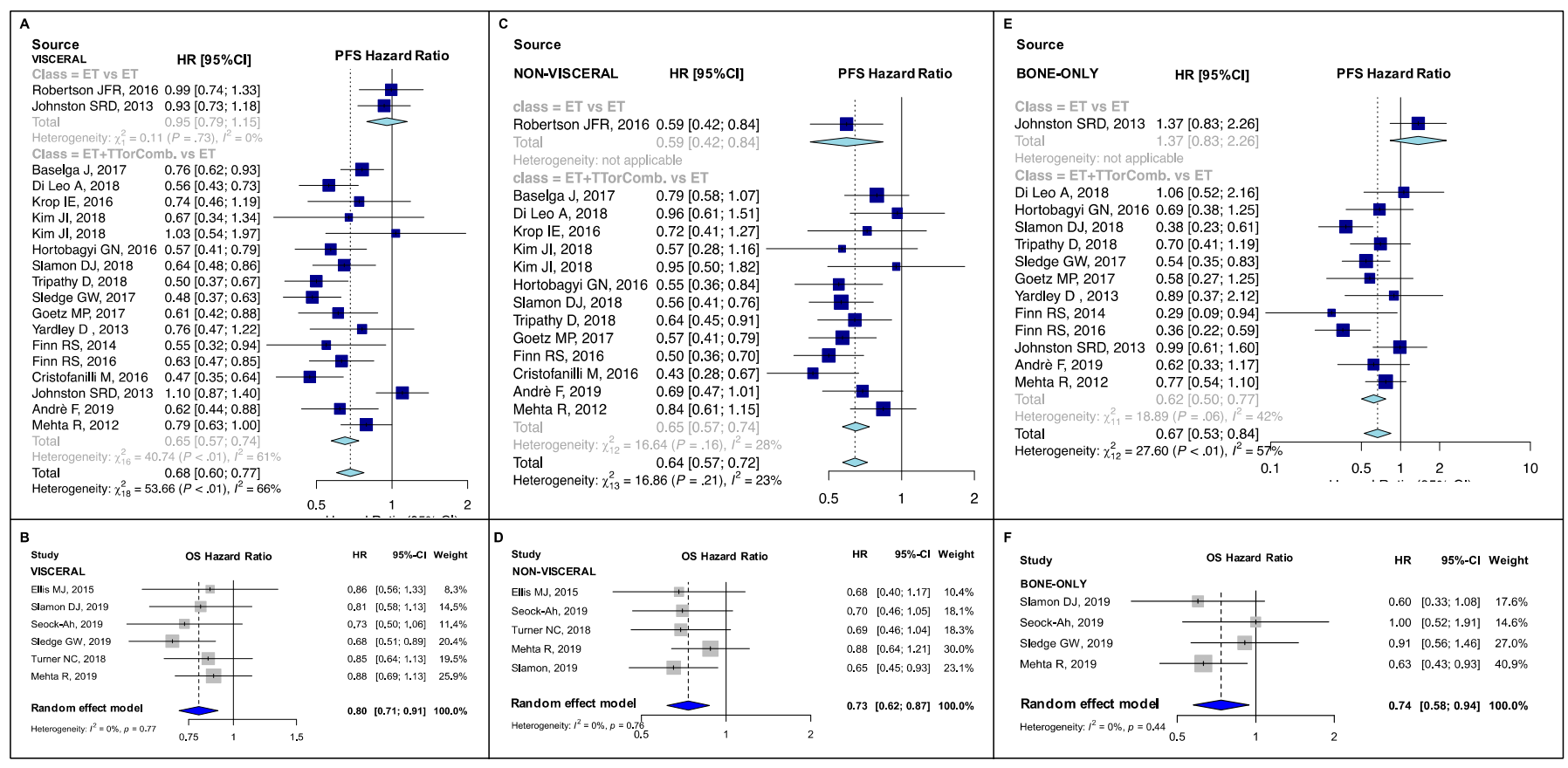

Figure 3. PFS and OS pooled results according to metastatic distribution: PFS pooled results for visceral (A), non-visceral (C) and bone-only disease (E) subgroups, overall and according to treatment strategy; and OS pooled results for visceral (B), non-visceral (D) and bone-only disease (F) subgroups. PFS, progression-free survival; OS, overall survival; ET vs. ET, studies comparing single endocrine agents therapies; ET + TT or Comb. vs. ET, studies comparing endocrine therapies + target therapies or endocrine therapies combinations against single agent endocrine treatments; $\mathrm{HR}$, hazard ratio; 95\% CI, $95 \%$ confidence interval.

A significant pooled OS improvement was also observed in almost all subgroups (HR range: $0.73-0.88, p$-value range: $<0.001-0.02$; $\mathrm{I}^{2}$ range: $0.00-59.9 \%$, $\mathrm{p}_{\mathrm{H}}$ range: $\left.0.003-0.77\right)$ except in the PIK3CA-mutant and non-mutant groups ( $\mathrm{p}_{\text {subgroup }}\left(\mathrm{p}_{\text {sub }}\right)=0.08$ and $\mathrm{p}_{\text {sub }}=0.94$, respectively) (Figure 2B,D, Figure 3B,D,F and Figure 4B,D). No high heterogeneity or publication bias was observed (Figure S1), except for the PFS endpoint in postmenopausal setting (Egger's test $p=0.009$ ). The results are detailed in Table 1 .

\subsection{Subgroup Analyses and Meta-Regressions: Combination Studies versus Single Agent Studies}

In postmenopausal patients, the subgroup analysis showed that PFS was significantly better in studies comparing ET+TT or ET combinations than in RCT of single agent ET ((HR: $0.63,95 \%$ CI: 0.56-0.71, I²: 78.8\%) vs. (HR: 0.82, 95\% CI: $\left.0.69-0.97, \mathrm{I}^{2}: 87.9 \%\right)$, $\mathrm{p}_{\text {sub }}=0.01$, Figure $2 \mathrm{~A}$ ); this result was also confirmed by the meta-regression analysis ( $\beta$ meta-regression $(\mathrm{m})$ : $-0.26, \mathrm{p}_{\mathrm{m}}=0.01$ ). The result was significant also in terms of OS ((HR: $0.82,95 \%$ CI: $\left.0.75-0.88, \mathrm{I}^{2}: 10.8 \%\right)$ vs. (HR: 0.98, 95\% CI: 0.77-1.24, $\mathrm{I}^{2}: 74.1 \%$ ), $\mathrm{p}_{\text {sub }}=0.03$, Figure $\left.2 \mathrm{~B} ; \beta_{\mathrm{m}}:-0.16, \mathrm{p}_{\mathrm{m}}=0.02\right)$

In patients with visceral disease, the pooled PFS was significantly better in combination studies than in single agent ET studies ((HR: 0.65, 95\% CI: 0.57-0.74, $\mathrm{I}^{2}: 60.7 \%$ ) vs. (HR: $0.95,95 \%$ CI: $0.79-1.15, I^{2}: 0.0 \%$ ), $p_{\text {sub }}<0.001$, Figure $3 \mathrm{~A} ; \beta_{\mathrm{m}}:-0.30, \mathrm{p}_{\mathrm{m}}=0.028$ ). No significant difference was observed in terms of OS $\left(\mathrm{p}_{\mathrm{sub}}=0.73\right)$. In non-visceral disease, there was no difference between the two study groups in terms of PFS $\left(p_{\text {sub }}=0.63\right)$ and OS $\left(\mathrm{p}_{\text {sub }}=0.77\right)$. Nevertheless, individual PFS results for both treatment subgroups were significant ((HR: 0.65, 95\% CI: 0.57-0.74, $\mathrm{I}^{2}: 27.9 \%$ ) vs. (HR: 0.59, 95\% CI: $0.42-0.84, \mathrm{I}^{2}$ : not evaluable); Figure 3C). Similar to the visceral subgroup, in MBC patients with boneonly disease, PFS was better in combination treatment studies than in those receiving ET alone ((HR: 0.62, 95\% CI: 0.50-0.77, I $\left.\mathrm{I}^{2}: 41.8 \%\right)$ vs. (HR: $1.37,95 \%$ CI: $\left.0.83-2.26, \mathrm{I}^{2}: 0.0 \%\right)$, $\mathrm{p}_{\mathrm{sub}}=0.004$, Figure $\left.3 \mathrm{E} ; \beta_{\mathrm{m}}:-0.79, \mathrm{p}_{\mathrm{m}}=0.03\right)$. This comparison was not possible for the OS endpoint. 


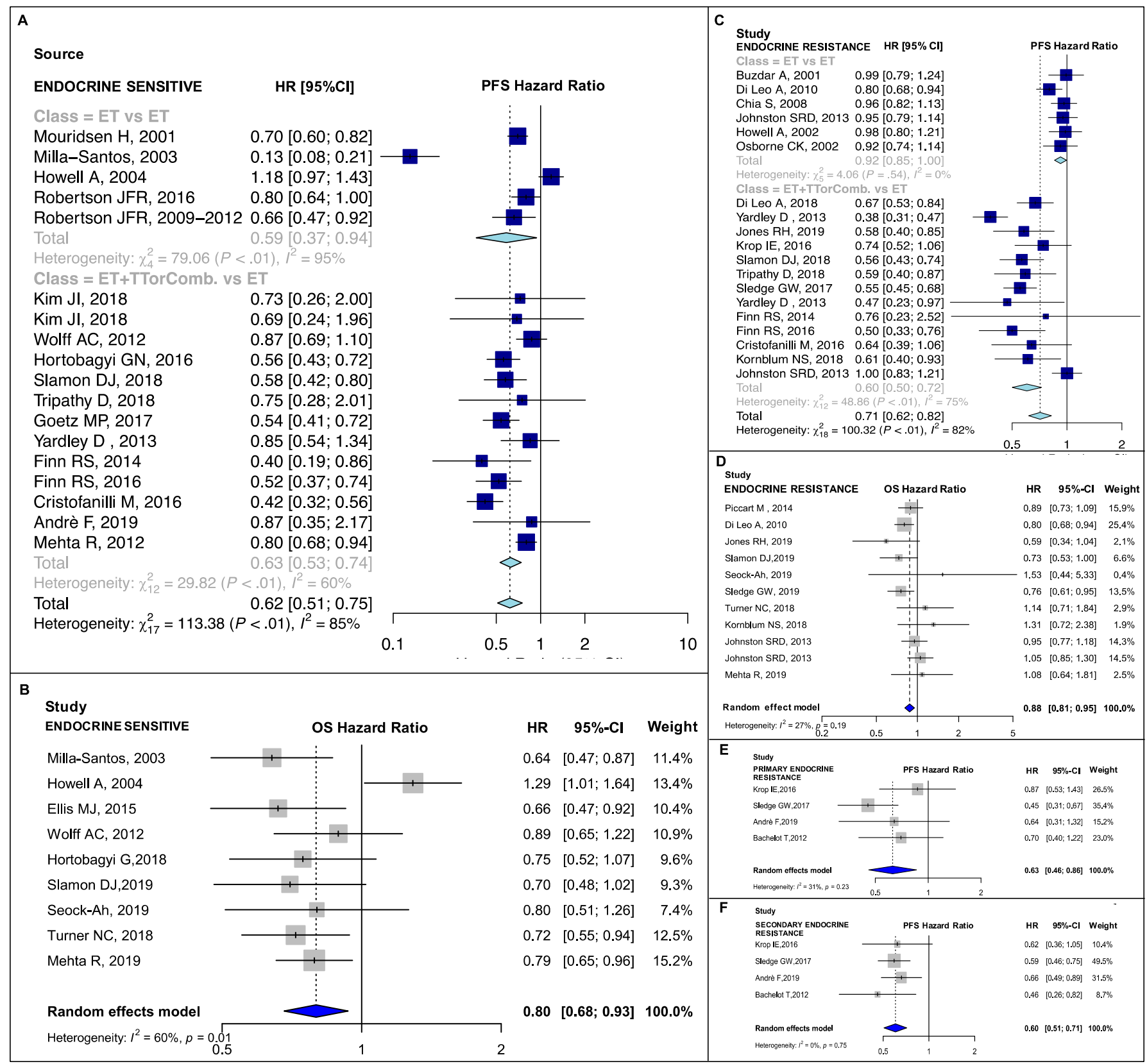

Figure 4. PFS and OS pooled results according to endocrine sensitiveness: PFS pooled result for the endocrine sensitive (A) and resistant (C) subgroups; OS pooled result for the endocrine sensitive (B) and endocrine resistant (D) subgroups; and PFS pooled result for the primary endocrine resistant (E) and secondary endocrine resistant (F) subgroups; PFS, progression-free survival; OS, overall survival; ET vs. ET, studies comparing single agents endocrine therapies; ET+TT or Comb. vs. ET, studies comparing endocrine therapies + target therapies or endocrine therapies combinations against single agent endocrine treatments; $\mathrm{HR}$, hazard ratio; 95\% CI, 95\% confidence interval. 


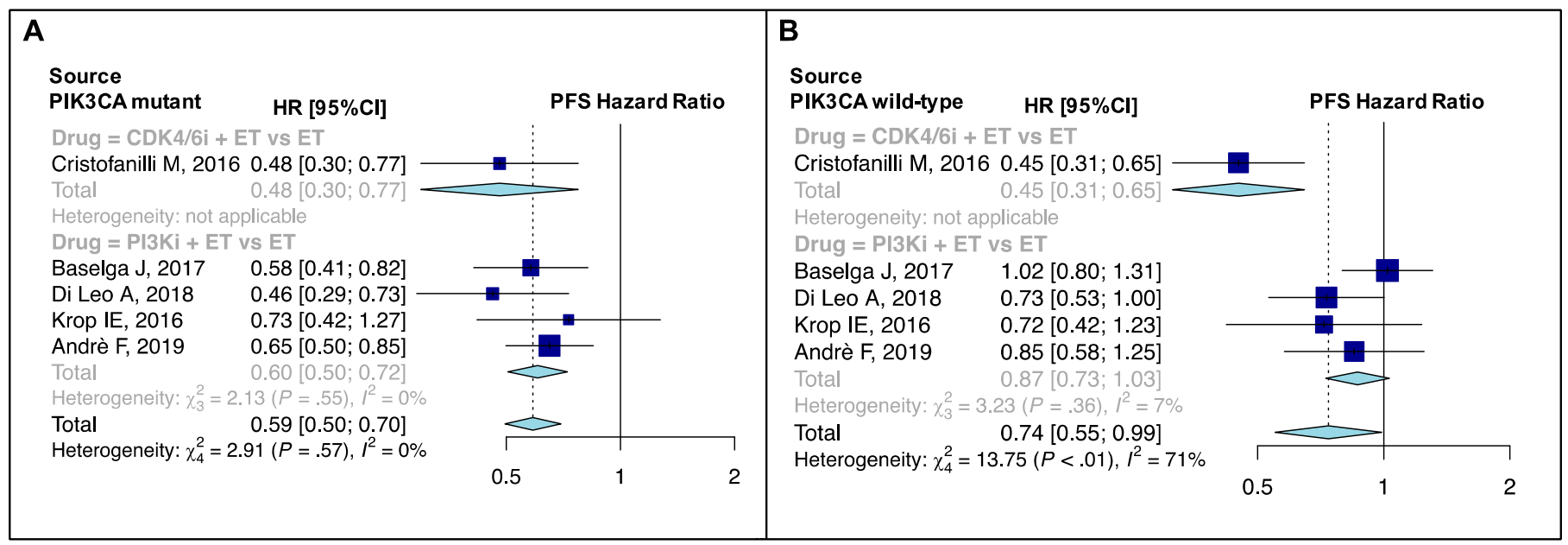

Figure 5. PFS pooled results according to PIK3CA mutational status: PFS pooled results for PIK3CA-mutant (A) and non-mutant (B) patients, overall and according to drug classes. PFS, progression-free survival; ET, endocrine therapy; HR, hazard ratio; 95\% CI, 95\% confidence interval. PI3Ki, phosphatidylinositol 3-kinases inhibitors; CDK4/6i, Cyclin-dependent kinases $4 / 6$ inhibitors.

Table 1. PFS and OS pooled results according to each patients' subgroup.

\begin{tabular}{|c|c|c|c|c|c|c|}
\hline \multicolumn{7}{|c|}{ PFS/TTP } \\
\hline \multirow{2}{*}{ Subset } & \multirow{2}{*}{ N. Comparisons ${ }^{b}$} & \multirow{2}{*}{ Pooled HR (95\% CI) } & \multirow{2}{*}{$I^{2.4}(\%)$} & \multirow{2}{*}{$p_{\text {pooled }}$} & \multirow{2}{*}{$p_{\text {heterogeneity }}$} & Publication Bias \\
\hline & & & & & & $($ Egger's Test $p)$ \\
\hline Pre/perimenopausal & 4 & $0.59(0.45-0.76)$ & $46.09 \%$ & $<0.001$ & 0.121 & $\mathrm{NE}$ \\
\hline Postmenopausal ${ }^{\mathrm{a}}$ & 32 & $0.70(0.63-0.78)$ & $86.2 \%$ & $<0.001$ & $<0.001$ & 0.009 \\
\hline Visceral & 19 & $0.68(0.60-0.77)$ & $66.50 \%$ & $<0.001$ & $<0.001$ & 0.47 \\
\hline Non-visceral & 14 & $0.64(0.57-0.72)$ & $22.90 \%$ & $<0.001$ & 0.21 & 0.74 \\
\hline Bone-only & 13 & $0.67(0.53-0.84)$ & $56.50 \%$ & $<0.001$ & 0.006 & 0.81 \\
\hline Endocrine Sensitive & 18 & $0.62(0.51-0.75)$ & $85.40 \%$ & $<0.001$ & $<0.001$ & 0.15 \\
\hline Endocrine Resistant & 19 & $0.71(0.62-0.82)$ & $82.10 \%$ & $<0.001$ & $<0.001$ & 0.09 \\
\hline Primary Resistance & 4 & $0.63(0.46-0.86)$ & $30.90 \%$ & 0.004 & 0.23 & $\mathrm{NE}$ \\
\hline Secondary Resistance & 4 & $0.60(0.51-0.71)$ & $0.00 \%$ & $<0.001$ & 0.75 & NE \\
\hline PIK3CA-mutant & 5 & $0.59(0.50-0.70)$ & $0.00 \%$ & $<0.001$ & 0.57 & $\mathrm{NE}$ \\
\hline PIK3CA-wild-type & 5 & $0.74(0.55-0.99)$ & $70.90 \%$ & 0.042 & $<0.001$ & NE \\
\hline \multicolumn{7}{|c|}{ OS } \\
\hline Pre/perimenopausal & 3 & $0.76(0.60-0.96)$ & $0.00 \%$ & 0.02 & 0.41 & $\mathrm{NE}$ \\
\hline Postmenopausal a & 21 & $0.85(0.77-0.94)$ & $55.0 \%$ & $<0.001$ & 0.003 & 0.47 \\
\hline Visceral & 6 & $0.80(0.71-0.91)$ & $0.00 \%$ & $<0.001$ & 0.77 & $\mathrm{NE}$ \\
\hline Non-visceral & 5 & $0.73(0.62-0.87)$ & $0.00 \%$ & $<0.001$ & 0.76 & $\mathrm{NE}$ \\
\hline Bone-only & 4 & $0.74(0.58-0.94)$ & $0.00 \%$ & 0.01 & 0.44 & $\mathrm{NE}$ \\
\hline Endocrine Sensitive & 9 & $0.80(0.68-0.93)$ & $59.9 \%$ & 0.005 & 0.01 & 0.44 \\
\hline Endocrine Resistant & 11 & $0.88(0.81-0.95)$ & $26.7 \%$ & 0.002 & 0.19 & 0.35 \\
\hline PIK3CA-mutant & 2 & $0.80(0.59-1.03)$ & $0.00 \%$ & 0.08 & 0.76 & $\mathrm{NE}$ \\
\hline PIK3CA-wild-type & 2 & $0.99(0.79-1.24)$ & $34.70 \%$ & 0.94 & 0.21 & NE \\
\hline
\end{tabular}

PFS, progression-free survival; TTP, time-to-progression; OS, overall survival; HR, hazard ratio; 95\% CI, 95\% confidence interval; NE: not estimable. ${ }^{a}$ Postmenopausal is here considered as only physiological or due to surgical castration before study enrollment. ${ }^{b}$ The number of comparisons can be superior to the number of studies.

With respect to the endocrine-sensitive subset, neither pooled PFS nor pooled OS differed significantly in relation to treatment strategy $\left(\mathrm{p}_{\text {sub }}=0.79\right.$ and $\mathrm{p}_{\text {sub }}=0.81$, respectively). Though, individual PFS results for both treatment subgroups were significant ((HR: 0.63, 95\% CI: 0.53-0.74, I²: 59.8\%) vs. (HR: 0.59, 95\% CI: 0.37-0.94, I²: 94.9\%), Figure 4A). On the contrary, in the endocrine-resistance setting, PFS was better in combination therapy studies than in single agent ET studies ((HR: 0.60, 95\% CI: 0.50-0.72, I²: 75.4\%) vs. (HR: 
$0.92,95 \%$ CI: 0.85-1.00, $\left.\mathrm{I}^{2}: 0.0 \%\right), \mathrm{p}_{\text {sub }}=0.001$, Figure $\left.4 \mathrm{C} ; \beta_{\mathrm{m}}:-0.43, \mathrm{p}_{\mathrm{m}}=0.001\right)$. There was a similar albeit not significant $\left(\mathrm{p}_{\mathrm{sub}}=0.81\right)$ effect on OS. Progression-free survival and OS subgroup analyses for the premenopausal setting, PIK3CA-mutant and non-mutant disease and primary and secondary endocrine resistance were not feasible. We were able to conduct meta-regression for the OS endpoint only in the postmenopausal subgroup, because in the other subgroups either the number of studies was too low $(<10)$ or subgroup analyses were not significant. PFS and OS results are detailed in Table 2 and Table S2, respectively.

\subsection{Subgroup Analyses and Meta-Regressions: Drug Class Comparisons}

Subgroup analysis of drug class revealed statistically significant differences in PFS in postmenopausal $\left(\mathrm{p}_{\mathrm{sub}}=0.01\right)$, visceral $\left(\mathrm{p}_{\mathrm{sub}}<0.001\right)$, non-visceral $\left(\mathrm{p}_{\mathrm{sub}}=0.008\right)$, bone-only $\left(p_{\text {sub }}=0.002\right)$, endocrine-sensitive $\left(p_{\text {sub }}<0.001\right)$, endocrine-resistant $\left(p_{\text {sub }}<0.001\right)$ and PIK3CA non-mutant $\left(\mathrm{p}_{\mathrm{sub}}=0.001\right)$ subgroups (Figure 5A,B and Figure S2). No difference was observed in the PIK3CA-mutant $\left(\mathrm{p}_{\text {sub }}=0.38\right)$ subgroup.

Studies of CDK4/6i-based regimens served as reference for the meta-regressions. In the postmenopausal setting, the most pronounced beneficial effects were observed in CDK4/6i-containing group (HR: 0.55, 95\% CI: 0.50-0.61) and in the group of AI compared to tamoxifen (HR: 0.44, 95\% CI: 0.21-0.92). Meta-regression analysis revealed a significantly worse effect for AI vs. progestins $\left(\beta_{\mathrm{m}}: 0.60, \mathrm{p}_{\mathrm{m}}=0.04\right)$, SERD + AI vs. SERD $\left(\beta_{\mathrm{m}}: 0.61\right.$, $\left.\mathrm{p}_{\mathrm{m}}=0.03\right)$ and SERD vs. AI or tamoxifen $\left(\beta_{\mathrm{m}}: 0.56, \mathrm{p}_{\mathrm{m}}<0.001\right)$ study groups compared to the reference group.

In patients with visceral disease, the best pooled result was found in studies of CDK4/6i-containing regimens (HR: 0.55, 95\% CI: 0.49-0.61). At meta-regression analysis, the beneficial effect was significantly less pronounced in PI3Ki-containing studies $\left(\beta_{\mathrm{m}}: 0.21\right.$, $\left.\mathrm{p}_{\mathrm{m}}=0.02\right)$, SERD + AI vs. AI $\left(\beta_{\mathrm{m}}: 0.36, \mathrm{p}_{\mathrm{m}}=0.006\right)$ and SERD vs. AI or tamoxifen $\left(\beta_{\mathrm{m}}: 0.55\right.$, $\left.\mathrm{p}_{\mathrm{m}}=0.001\right)$ study groups, and a significant detrimental effect was observed in the SERD + AI vs. SERD group ( $\beta_{\mathrm{m}}: 0.69, \mathrm{p}_{\mathrm{m}}<0.001$; Figure $\left.\mathrm{S} 2\right)$. In the non-visceral setting, CDK4/6icontaining studies showed the best pooled result (HR: 0.55, 95\% CI: 0.47-0.63). Compared to the latter group, the beneficial effect was significantly lower in the PI3Ki-containing studies $\left(\beta_{\mathrm{m}}: 0.36, \mathrm{p}_{\mathrm{m}}=0.004\right)$, followed by the SERD+AI vs. AI group $\left(\beta_{\mathrm{m}}: 0.43, \mathrm{p}_{\mathrm{m}}=0.01\right.$; Figure S2). No difference was observed in the SERD vs. AI or tamoxifen group (HR: 0.59, 95\% CI: 0.42-0.84; $\left.\mathrm{p}_{\mathrm{m}}=0.67\right)$.

In bone-only disease, a numerically significant pooled PFS benefit was observed only in the CDK4/6i+ET vs. ET subgroup (HR: 0.50, 95\% CI: 0.40-0.62). Meta-regression analysis revealed a statistically significant inferiority in studies investigating the combination of SERD + AI vs. SERD $\left(\beta_{\mathrm{m}}: 0.69, \mathrm{p}_{\mathrm{m}}=0.018\right)$ and SERD vs. AI or tamoxifen $\left(\beta_{\mathrm{m}}: 1.01\right.$, $\mathrm{p}_{\mathrm{m}}<0.001 \%$; Figure S2). In the endocrine-sensitive setting, the effect seemed to be more pronounced in the CDK4/6i+ET vs. ET group (HR: 0.52, 95\% CI: 0.46-0.59; Figure S2). In the endocrine-resistance setting, the study group showing the best result was the one containing mTORi (HR: 0.47, 95\% CI: 0.29-0.74). At meta-regression analysis, the beneficial effect was significantly greater in the mTORi + ET vs. ET studies $\left(\beta_{m}:-0.29, p_{m}=0.016\right)$ and significantly lower in the studies comparing SERD to AI or tamoxifen $\left(\beta_{\mathrm{m}}: 0.53\right.$, $\left.\mathrm{p}_{\mathrm{m}}<0.001\right)$ and SERD+AI to SERD $\left(\beta_{\mathrm{m}}: 0.57, \mathrm{p}_{\mathrm{m}}<0.001\right.$; Figure S2) compared to the reference group.

In PIK3CA-mutant patients, the two drug classes compared, namely CDK4/6i and PI3Ki, both resulted in a better PFS vs. standard ET (HR: 0.48, 95\% CI: 0.30-0.77 and HR: 0.60, 95\% CI: 0.50-0.72, respectively; Figure 5A). On the contrary, in PIK3CA wildtype patients only CDK4/6i-containing studies provided a significant PFS improvement (HR: 0.45, 95\% CI: 0.31-0.65; Figure 5B) compared to PI3Ki-containing studies.

Subgroup analyses for OS were not statistically significant (Table S2). PFS and OS subgroup analyses according to drug class comparisons were not feasible for the pre/ perimenopausal, primary and secondary endocrine-resistance subgroups. Meta-regression could not be performed for the OS endpoint, except in the postmenopausal setting. 
Table 2. The results of PFS/TTP subgroup analyses and meta-regressions for treatment categories and drug classes.

\begin{tabular}{|c|c|c|c|c|c|c|c|}
\hline Subsets & Comparisons & N. Comparisons & Pooled HR & $p_{\text {subgroup }}$ & $I^{2}(\%)$ & $\beta_{\text {meta-regression }}$ & $p_{\text {meta-regression }}$ \\
\hline \multirow{2}{*}{ Postmenopausal ${ }^{\text {a }}$} & ET vs. ET & 13 & $0.82(0.69-0.97)$ & \multirow{2}{*}{0.01} & $87.9 \%$ & Reference & \multirow{2}{*}{0.01} \\
\hline & ET + TTorComb. vs. ET & 19 & $0.63(0.56-0.71)$ & & $78.8 \%$ & -0.16 & \\
\hline \multirow{10}{*}{ Postmenopausal a } & CDK4/6i + ET vs. ET & 7 & $0.55(0.50-0.61)$ & \multirow{10}{*}{0.01} & $0.0 \%$ & Reference & - \\
\hline & AI vs. Progestins & 1 & $0.99(0.79-1.24)$ & & NE & 0.60 & 0.04 \\
\hline & AI vs. SERM & 3 & $0.44(0.21-0.92)$ & & $96.2 \%$ & -0.08 & 0.70 \\
\hline & AKTi + ET vs. ET & 1 & $0.58(0.40-0.85)$ & & NE & 0.07 & 0.84 \\
\hline & HDACi + ET vs. ET & 1 & $0.73(0.50-1.07)$ & & NE & 0.30 & 0.38 \\
\hline & mTORi + ET vs. ET & 4 & $0.58(0.36-0.94)$ & & $92.1 \%$ & 0.07 & 0.68 \\
\hline & PI3Ki + ET vs. ET & 4 & $0.73(0.66-0.81)$ & & $0.0 \%$ & 0.27 & 0.13 \\
\hline & SERD + AI vs. AI & 1 & $0.80(0.68-0.94)$ & & NE & 0.39 & 0.17 \\
\hline & SERD + AI vs. SERD & 1 & $1.00(0.83-1.21)$ & & NE & 0.61 & 0.03 \\
\hline & SERD vs. AI/SERM & 8 & $0.96(0.85-1.08)$ & & $55.0 \%$ & 0.56 & $<0.001$ \\
\hline \multirow{2}{*}{ Visceral } & ET vs. ET & 2 & $0.95(0.79-1.15)$ & \multirow{2}{*}{$<0.001$} & $0.00 \%$ & & \multirow{2}{*}{0.028} \\
\hline & $\mathrm{ET}+\mathrm{TT}$ or ET comb. vs. ET & 17 & $0.65(0.57-0.74)$ & & $60.70 \%$ & -0.30 & \\
\hline \multirow{5}{*}{ Visceral } & CDK4/6i + ET vs. ET & 8 & $0.55(0.49-0.61)$ & \multirow{5}{*}{$<0.001$} & $0.00 \%$ & Reference & \\
\hline & HDACi + ET vs. ET & 1 & $0.76(0.47-1.22)$ & & NE & 0.36 & 0.19 \\
\hline & PI3Ki + ET vs. ET & 4 & $0.67(0.57-0.79)$ & & $16.00 \%$ & 0.21 & 0.02 \\
\hline & SERD + AI vs. SERD & 1 & $1.10(0.87-1.40)$ & & NE & 0.69 & 0.001 \\
\hline & SERD vs. AI/SERM & 2 & $0.95(0.79-1.15)$ & & $0.00 \%$ & 0.55 & 0.001 \\
\hline \multirow{2}{*}{ Non-visceral } & ET vs. ET & 1 & $0.59(0.42-0.84)$ & \multirow[b]{2}{*}{0.63} & NE & Reference & \\
\hline & $\mathrm{ET}+\mathrm{TT}$ or ET comb. vs. ET & 13 & $0.65(0.57-0.74)$ & & $27.90 \%$ & 0.09 & 0.69 \\
\hline \multirow{4}{*}{ Non-visceral } & CDK4/6i + ET vs. ET & 6 & $0.55(0.47-0.63)$ & \multirow{4}{*}{0.008} & $0.00 \%$ & Reference & \\
\hline & PI3Ki + ET vs. ET & 4 & $0.78(0.64-0.95)$ & & $0.00 \%$ & 0.36 & 0.004 \\
\hline & SERD + AI vs. AI & 1 & $0.84(0.61-1.15)$ & & NE & 0.43 & 0.01 \\
\hline & SERD vs. AI/SERM & 1 & $0.59(0.42-0.84)$ & & $\mathrm{NE}$ & 0.08 & 0.67 \\
\hline \multirow{2}{*}{ Bone-only } & ET vs. ET & 1 & $1.37(0.83-2.26)$ & \multirow[b]{2}{*}{0.004} & NE & Reference & \\
\hline & $\mathrm{ET}+\mathrm{TT}$ or ET comb. vs. ET & 12 & $0.62(0.50-0.77)$ & & $41.80 \%$ & -0.79 & 0.03 \\
\hline \multirow{6}{*}{ Bone-only } & CDK4/6i + ET vs. ET & 7 & $0.50(0.40-0.62)$ & \multirow{6}{*}{0.002} & $10.70 \%$ & Reference & \\
\hline & HDACi + ET vs. ET & 1 & $0.89(0.37-2.12)$ & & NE & 0.58 & 0.21 \\
\hline & PI3Ki + ET vs. ET & 2 & $0.79(0.47-1.34)$ & & $17.70 \%$ & 0.46 & 0.09 \\
\hline & SERD +AI vs. AI & 1 & $0.77(0.54-1.10)$ & & NE & 0.44 & 0.07 \\
\hline & SERD+AI vs. SERD & 1 & $0.99(0.61-1.60)$ & & NE & 0.69 & 0.018 \\
\hline & SERD vs. AI/SERM & 1 & $1.37(0.83-2.56)$ & & $\mathrm{NE}$ & 1.01 & 0.001 \\
\hline
\end{tabular}


Table 2. Cont.

\begin{tabular}{|c|c|c|c|c|c|c|c|}
\hline Subsets & Comparisons & N. Comparisons & Pooled HR & $p_{\text {subgroup }}$ & $I^{2}(\%)$ & $\beta_{\text {meta-regression }}$ & $p_{\text {meta-regression }}$ \\
\hline \multirow{2}{*}{ Endocrine Sensitive } & ET vs. ET & 5 & $0.59(0.37-0.94)$ & \multirow[b]{2}{*}{0.79} & $94.90 \%$ & Reference & \\
\hline & $\mathrm{ET}+\mathrm{TT}$ or ET comb. vs. ET & 13 & $0.63(0.53-0.74)$ & & $59.80 \%$ & 0.039 & 0.85 \\
\hline \multirow{6}{*}{ Endocrine Sensitive } & CDK4/6i + ET vs. ET & 7 & $0.52(0.46-0.59)$ & \multirow{6}{*}{$<0.001$} & $0.00 \%$ & Reference & \\
\hline & AI vs. SERM & 2 & $0.31(0.06-1.59)$ & & $97.8 \%$ & -0.43 & 0.21 \\
\hline & HDACi + ET vs. ET & 1 & $0.85(0.54-1.34)$ & & NE & 0.43 & 0.31 \\
\hline & mTORi + ET vs. ET & 1 & $0.87(0.69-1.10)$ & & NE & 0.51 & 0.24 \\
\hline & PI3Ki + ET vs. ET & 1 & $0.87(0.35-2.17)$ & & NE & 0.51 & 0.41 \\
\hline & SERD + AI vs. AI & 1 & $0.80(0.68-0.94)$ & & NE & 0.43 & 0.32 \\
\hline \multirow{2}{*}{ Endocrine Resistance } & ET vs. ET & 6 & $0.92(0.85-1.00)$ & \multirow{2}{*}{$<0.001$} & $0.00 \%$ & Reference & \\
\hline & ET + TT or ET comb. vs. ET & 13 & $0.60(0.50-0.72)$ & & $75.40 \%$ & -0.43 & 0.001 \\
\hline \multirow{7}{*}{ Endocrine Resistance } & CDK4/6i + ET vs. ET & 6 & $0.56(0.49-0.65)$ & \multirow{7}{*}{$<0.001$} & $0.00 \%$ & Reference & \\
\hline & AKTi + ET vs. ET & 1 & $0.58(0.40-0.85)$ & & NE & 0.03 & 0.88 \\
\hline & AI vs. Progestins & 1 & $0.99(0.79-1.24)$ & & $\mathrm{NE}$ & 0.56 & 0.001 \\
\hline & HDACi + ET vs. ET & 1 & $0.47(0.23-0.97)$ & & $\mathrm{NE}$ & -0.18 & 0.62 \\
\hline & mTORi + ET vs. ET & 2 & $0.47(0.29-0.74)$ & & $74.30 \%$ & -0.29 & 0.016 \\
\hline & PI3Ki + ET vs. ET & 2 & $0.69(0.57-0.84)$ & & $0.00 \%$ & 0.2 & 0.092 \\
\hline & SERD vs. AI/SERM & 4 & $0.95(0.87-1.05)$ & & $0.00 \%$ & 0.53 & 0.001 \\
\hline \multirow{2}{*}{ PIK3CA-mutant } & CDK4/6i + ET vs. ET & 1 & $0.48(0.30-0.77)$ & \multirow{2}{*}{0.38} & NE & \multirow{2}{*}{$\mathrm{NE}$} & \multirow{2}{*}{$\mathrm{NE}$} \\
\hline & PI3Ki + ET vs. ET & 4 & $0.60(0.50-0.72)$ & & $0.00 \%$ & & \\
\hline \multirow{2}{*}{ PIK3CA-wild-type } & CDK4/6i + ET vs. ET & 1 & $0.45(0.31-0.65)$ & \multirow{2}{*}{0.001} & NE & \multirow{2}{*}{$\mathrm{NE}$} & \multirow{2}{*}{$\mathrm{NE}$} \\
\hline & PI3Ki + ET vs. ET & 4 & $0.87(0.72-1.03)$ & & $7.20 \%$ & & \\
\hline
\end{tabular}

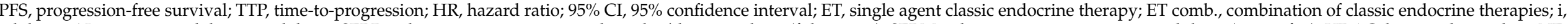

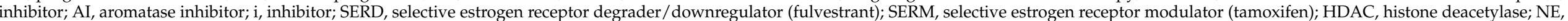
not estimable. ${ }^{a}$ Postmenopausal is here considered as only physiological or due to surgical castration before study enrollment. 


\subsection{Risk of Bias Analysis}

The risk of bias analysis did not reveal a relevant risk of bias for five out of seven domains (Figure 6).

However, there was a $29 \%$ high risk of selective reporting bias/incomplete outcomeattrition bias, because 10 studies did not report OS outcome (Figure S3). Moreover, randomization and the methodology applied to assign patients to each treatment arm were not clear in 16 studies (47\%), thus increasing the risk of selection bias (Figure S3).

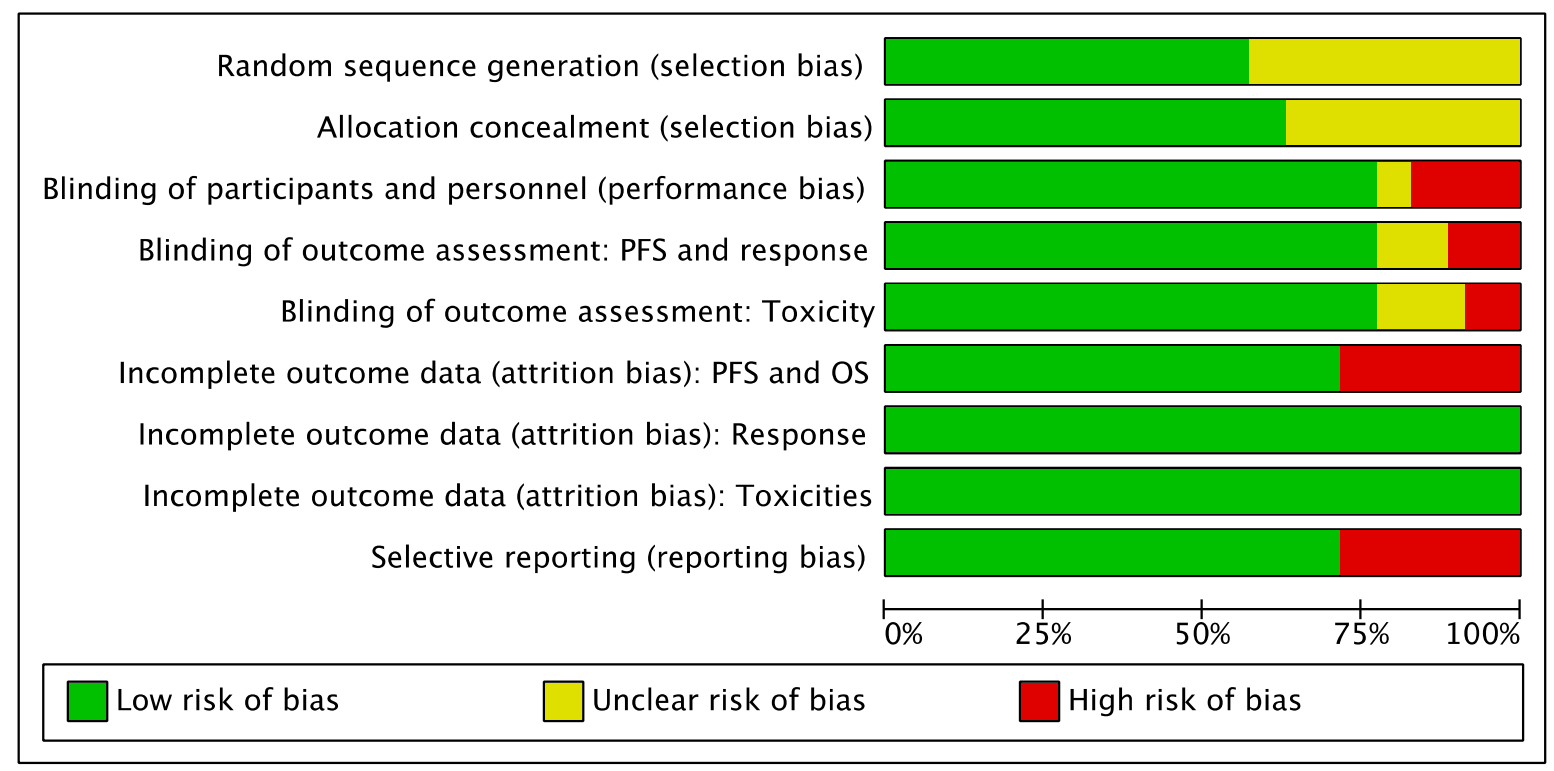

Figure 6. Risk of bias analysis.

\section{Discussion}

Based on our pooled results, we estimated that the novel ET \pm TT introduced in the last 20 years, compared to the older endocrine therapeutic standards, produced a relative reduction in the risk of disease progression ranging from $41 \%$ to $26 \%$ and a relative reduction in the risk of death ranging from $27 \%$ to $12 \%$, depending on the clinical subset.

\subsection{Postmenopausal, Visceral and Endocrine-Resistant Disease Subgroups}

When we compared the different treatment strategies, combination regimens appeared to be favored over single agent ET in the postmenopausal, visceral and endocrine-resistant subgroups of patients. In fact, targeted agents are expected to boost the effect of single agent ET by reverting the molecular mechanisms of endocrine resistance [53]. They usually also provide an additional intrinsic antitumor effect. When further dissecting these results according to drug class, only the group of studies containing CDK4/6i-combinations provided significant individual pooled PFS and OS results versus the other treatment groups. Nevertheless, the OS differences observed in the three subgroups did not reach statistical significance, most likely due to a lack of statistical power. In fact, significant results were obtained in almost all subgroups when all results were pooled.

In the endocrine-resistant subset, the best result was obtained in the mTORi-containing group, which was also favored over the CDK4/6i group at the meta-regression. This was not completely unexpected given the degree of benefit $(60 \%$ reduction in the risk of progression) obtained with everolimus + exemestane in the $\mathrm{BOLERO} 2$ trial in a context of substantial endocrine resistance [2]. In fact, many pathways of resistance converge on mTOR [54]. In addition, the sensitivity to CDK4/6i requires an intact Cyclin D1/Rb/E2F axis, and many of the signaling pathways that jeopardize sensitivity to endocrine therapy also lead to CDK4/6i resistance [55]. However, concerns have arisen over a potentially 
significant under powerfulness of the exemestane arm of the BOLERO 2 trial, due to the post-hoc finding of ESR1 mutations that might have prevented exemestane from producing any benefit, whereas a PFS improvement was observed with everolimus irrespective of patients' mutational status [56]. Moreover, the CDK4/6i-containing group was the only group showing an individually significant pooled OS result in this subset, concordantly with what is observed in a recently published meta-analysis on CDK4/6i OS benefit [11]. Our result was mostly driven by the MONARCH-2 abemaciclib-containing study, similar to what occurs in the setting of primary endocrine resistance. In case of secondary endocrine resistance, the overall reduction in the risk of progression of around $40 \%$ was driven by everolimus-, alpelisib- (in PIK3CA-mutant patients) and abemaciclib-containing combinations. This suggests that abemaciclib might play a relevant role in the treatment of endocrine-resistant tumors. Unfortunately, our results of primary and secondary endocrine resistance should be taken with caution, due to the very limited number of studies with available results for these subgroups. Finally, positive individual PFS results in the AKTiand HDACi-containing groups suggest that these drug classes might play a role in early treatment lines of endocrine-resistant disease. However, negative results for the E2112 phase III trial of entinostat + exemestane vs. exemestane in AI resistant HR+/HER2- MBC have been recently presented [57]. Hence, the future of HDACi in this clinical setting is uncertain. Conversely, the phase III CAPItello-291 trial is currently recruiting patients to confirm the efficacy of capivasertib + fulvestrant combination in AI-resistant HR+/HER2MBC (ClinicalTrials.gov Identifier: NCT 04305496).

\subsection{Bone-Only, Endocrine-Sensitive and Non-Visceral Disease Subgroups}

Notably, ET + TT was more effective in bone-only disease than ET alone, despite the fact that this subgroup of tumors is usually considered an indolent, slow-growing, prognostically better entity than the other clinical subgroups of breast cancer [58,59], making it more difficult, in principle, to identify an additional beneficial effect from combination strategies. This result was driven by CDK4/6i studies, because it was the only group in which there was a significant and profound PFS benefit. This result is also concordant both with a recent meta-analysis conducted in the same subset testing multiple types of ET [58], and with a recent US Food and Drug Administration meta-analysis on CDK4/6i [60]. However, a severe disproportion of RCT between single agent and combination treatment study groups (1 vs. 12) should be considered in this context. Moreover, the only study of the single agent group compared fulvestrant at a suboptimal dosage to an $\mathrm{AI}$ in the secondary endocrine resistance subset, with negative results. Therefore, we cannot formally exclude the possibility that single agent ET might be a valid option for bone-only disease.

In endocrine-sensitive disease, there was no difference between combination treatments and single agent endocrine therapy. However, it is important to highlight that both strategies improved PFS. The subgroup analysis according to drug class revealed that CDK4/6i-containing studies had both the greatest PFS benefit and the numerically highest OS benefit, although the subgroup analysis was not statistically significant for OS.

Similarly, treatment strategies did not differ significantly in non-visceral disease, perhaps due to the greater efficacy displayed by fulvestrant over anastrozole in the firstline FALCON phase III trial [48], which was the only study contributing to the single agent group. In the subgroup analysis according to drug class, CDK4/6i-containing studies, compared to the other classes, had the most powerful effect. This result was confirmed in the meta-regression analysis, although a comparable effect was observed with fulvestrant. In terms of OS, only CDK4/6i-based regimens retained a significant individual result, which suggests that CDK4/6i-based regimens are the best option also in patients with non-visceral disease, as also suggested elsewhere [11]. However, in endocrine-sensitive tumors without visceral involvement, fulvestrant might be a valuable first-line option for selected patients (e.g., patients with contraindications to CDK4/6i). 


\subsection{PIK3CA Mutational Status}

In the PIK3CA wild-type setting, CDK4/6i drove the overall PFS benefit observed over ET, whereas in PIK3CA-mutant patients, PFS was significantly better in both PI3Ki- and CDKi-containing groups versus single-agent ET. Interestingly, partial results of the BYLieve trial have been recently reported, confirming the efficacy of PI3Ki + ET in PIK3CA-mutant patients, even if pre-treated with CDK4/6i [61]. At the same time, modest results have been recently observed with the PI3Ki taselisib in combination with fulvestrant in AI-pretreated HR+/HER2- MBC in the SANDPIPER phase III trial [62]. Overall, our results, put into context, indicate that the efficacy of CDK4/6i + ET is not affected by PIK3CA mutational status and can thus be used in both PIK3CA-mutant and wild-type patients, while PI3Ki + ET combinations might play a significant role in the early treatment of patients whose tumors harbor PIK3CA mutations and can be used after CDK4/6i-based combinations, without significant concerns regarding their efficacy. However, not all PI3Ki are the same and only alpelisib has thus far shown an adequate therapeutic efficacy associated to a sufficiently manageable toxicity profile.

\subsection{Limitations and Strengths}

Our study has several limitations. First, not being a network meta-analysis, we were unable to directly compare all drugs or combinations of drugs to one and another. Consequently, some degree of precision was lost. Moreover, we were not able to conduce separate in-depth analyses for first- and second-line, since the majority of studies included patients from both treatment lines and did not provide separate results. Additionally, our analysis did not include toxicity comparisons, as well as quality of life (QoL), being essentially focused on survival endpoints. Nevertheless, a previous work from our group comprehensively resumed main toxicities for all available single agent ET, CT and ET + TT combinations, including treatments analyzed in the present study [19]. Differently, QoL is difficult to evaluate in a meta-analyses such as ours that include numerous studies involving a high number of different drugs/regimens. In any case, although QoL was not assessed and/or not reported for $22(62.9 \%)$ of the included RCT, we briefly resumed available results in Table S1. No differences between experimental and standard arms were the most frequently reported outcome and CDK4/6i-based combinations were the ones most frequently ameliorating patients' QoL, compared to standard treatment arm.

We were not able to perform an individual patient data (IPD) meta-analysis, due to the lack of the necessary resources. In any case, it is worth mentioning that for meta-analyses of published time-to-event outcomes as ours, individual case studies have shown that they can produce effects that are larger than, smaller than, or similar to their IPD equivalents [63]. Moreover, hazard ratios from published aggregate patients' data (APD) meta-analyses seem to most likely agree with those from IPD, when the information size is large [64].

Finally, we assessed the presence of publication bias through funnel plots inspection and Egger's test (when applicable), whose use and interpretation have been controversial because of concerns about statistical validity, appropriate interpretation and low power of the tests $[65,66]$. However, they still represent the standard recommended and most easy-tointerpret techniques [67]. In any case, the presence of publication bias was only observed for the PFS postmenopausal pooled result, where this outcome was not completely unexpected, due to a potential "selective analysis reporting" [68]. In fact, for the scope of our study, we excluded all RCT regarding endocrine agents and combinations not used in clinical practice over the last 20 years or not sufficiently promising to be expected to be introduced into the clinical scenario within a reasonable time. Most of these drugs were investigated precisely in the postmenopausal setting.

To our knowledge, this analysis is the first to produce a comprehensive and contextualized evaluation of the impact on disease progression delay and survival increase of endocrine-based treatments developed in the last 20 years, which specifically focused on specific disease settings of clinical relevance. In this view, strengthening the efficacy of $\mathrm{ET} \pm \mathrm{TT}$, especially in the visceral and endocrine resistant subgroups, two controversial 
subsets when considering the issue of the overuse of upfront CT [69-72], is of outmost importance to ultimately provide patients with the most efficacious treatment options. Despite numerous therapeutic advances, we were also able to identify a potentially tailored role for upfront single agent ET in the era of TT-based combinations. Heterogeneity was properly assessed by adopting a random-effect model, with subgroup analyses and metaregressions. Finally, the risk of bias analysis did not raise substantial concerns regarding the internal validity of the studies included.

\section{Conclusions}

Combination strategies appear to be more beneficial than single agent ET in the treatment of postmenopausal, visceral, bone-only and endocrine-resistant tumors, while single agent ET might still be considered in selected cases for the upfront treatment of endocrinesensitive tumors and in tumors without metastatic visceral involvement. CDK4/6i+ET combinations were the most effective treatment in the first-/second-line settings irrespective of tumor metastatic distribution and PIK3CA mutational status, as well as in endocrine-sensitive tumors. In the case of endocrine-resistance, CDK4/6i-based regimens were significantly and consistently effective in prolonging both PFS and OS, however mTORi-based regimens were apparently favored over the others, although some concern remains regarding this result. PI3Ki + ET regimens were effective in PIK3CA-mutant patients. Overall, we provide strong evidence to further support the main international treatment guidelines [16-18] and to help clinicians in tailoring their treatment choices in specific patients' subgroups.

Supplementary Materials: The following are available online at https://www.mdpi.com/2072-6 694/13/6/1458/s1, Figure S1: Funnel plots, Figure S2: PFS according to drug class comparisons, Figure S3: Detailed risk of bias analysis for each study, Table S1: Characteristics of the included trials, Table S2: Overall survival analyses according to treatment category and drug class, Text S1: Supplementary Methods. References [73-85] are cited in the Supplementary Materials.

Author Contributions: F.S. and D.G. conceived the study. F.S., C.R., B.C. and P.D.P. performed the systematic review of the literature. D.G. was consulted for a final decision in case of controversy. F.G. and F.S. performed the statistical analyses. All authors contributed to interpreting the data, revised the work critically for important intellectual content, approved the final version of the manuscript and agree to be accountable for all aspects of the work in ensuring that questions related to the accuracy or integrity of any part of the work are appropriately investigated and resolved. All authors have read and agreed to the published version of the manuscript.

Funding: This research was supported by Mednote, spin-off-University of Trieste-Mozart Program. This work was supported in part by the Programma di Ricerca Scientifica di Rilevante Interesse Nazionale (PRIN) 2017 "Extracellular vesicles in cancer development, progression and drug resistance: potential biomarkers and therapeutic targets"', number: 2017EKMFTN_006 (to Dr. Schettini and Giuliano). Dr. Schettini is recipient of an ESMO Fellowship.

Institutional Review Board Statement: Not applicable.

Informed Consent Statement: Not applicable.

Data Availability Statement: The databases for the analyses of this study are available on request from the corresponding author.

Acknowledgments: We thank Jean Ann Gilder (Scientific Communication SRL, Naples, Italy) for proofreading and editing the article.

Conflicts of Interest: The funders had no role in the design of the study; in the collection, analyses, or interpretation of data; in the writing of the manuscript, or in the decision to publish the results. Any views, opinions, findings, conclusions, or recommendations expressed in this material are those solely of the author(s) and do not necessarily reflect those of the funders. Outside of the submitted work, Mario Giuliano and Sabino De Placido have declared honoraria from Roche, Pfizer, Astra-Zeneca, Novartis, Celgene, Eli Lilly, Amgen and Eisai. Aleix Prat has declared an immediate family member being employed by Novartis, personal honoraria from Pfizer, Novartis, Roche, MSD Oncology, 
Lilly and Daiichi Sankyo; travel, accommodations and expenses paid by Daiichi Sankyo; research funding from Roche and Novartis; consulting/advisory role for NanoString Technologies, Amgen, Roche, Novartis, Pfizer and Bristol-Myers Squibb; and patent PCT/EP2016/080056: HER2 AS A PREDICTOR OF RESPONSE TO DUAL HER2 BLOCKADE IN THE ABSENCE OF CYTOTOXIC THERAPY. Guy Jerusalem has reported grants, personal fees and non-financial support from Novartis; grants, personal fees and non-financial support from Roche; grants, personal fees and non-financial support from Pfizer; personal fees and non-financial support from Lilly; personal fees and nonfinancial support from Amgen; personal fees and non-financial support from BMS; personal fees and non-financial support from Astra-Zeneca; personal fees and non-financial support from Daiichi Sankyo; personal fees from Abbvie; non-financial support from Medimmune; and non-financial support from MerckKGaA. Angelo Di Leo has reported advisory board, consultant and honoraria from AZ, Bayer, Celgene, Daiichi-Sankyo, Eisai, Genomic Health, Genentech, Ipsen, Lilly, Novartis, Puma Biotechnology, Pfizer and Roche. Lucia Del Mastro has declared honoraria from Roche, Pfizer, Ipsen, Eli Lilly, Eisai, Novartis, Takeda and MSD; consulting/advisory role for Roche and Eli Lilly; and travel, accommodation and expenses from Roche, Pfizer and Celgene. Fabio Puglisi has declared honoraria for advisory boards; activities as a speaker from Amgen, Astra-Zeneca, Celgene, Eisai, Eli Lilly, Ipsen, MSD, Novartis, Pierre-Fabre, Pfizer, Roche and Takeda; travel grants from Celgene and Roche; and research funding from Astra-Zeneca, Eisai, Roche and Italian Ministry of Health. PierFranco Conte has declared consultant role for Novartis, Eli Lilly, Astra Zeneca and Tesaro; honoraria from BMS, Roche, Eli Lilly, Novartis and AstraZeneca; and research funding from Novartis, Roche, BMS, Merck-KGa, Italian Ministry of Health, Veneto Secretary of Health and University of Padova. Rachel Schiff has declared research funding from AstraZeneca, GlaxoSmithKline, Gilead Sciences, Eli Lilly, and PUMA Biotechnology and consulting/advisory role with compensation for Macrogenics and Eli Lilly. C. Kent Osborne has declared research funding from AstraZeneca and GlaxoSmithKline; advisory boards for Tolmar Pharmaceuticals, Genentech, and AstraZeneca; DMC for Eli Lilly; and stockholder of GeneTex. Mothaffar F. Rimawi has declared research funding from GlaxoSmithKline and Genentech. Lajos Pusztai has received consulting fees and honoraria from Seagen, Pfizer, Astra Zeneca, Merck, Novartis, Bristol-Myers Squibb, Pfizer, Genentech, Eisai, Pieris, Immunomedics, Clovis, Syndax, H3Bio, Radius Health, and Daiichi and institutional research funding from Seagen, AstraZeneca, Merck, Pfizer and Bristol Myers Squibb. Daniele Generali has declared consulting fees from Novartis, Lilly and Pfizer and research funding from LILT, Novartis Astra-Zeneca and University of Trieste. The other authors have nothing to declare.

\section{References}

1. Prat, A.; Pineda, E.; Adamo, B.; Galván, P.; Fernández, A.; Gaba, L.; Díez, M.; Viladot, M.; Arance, A.; Muñoz, M. Clinical implications of the intrinsic molecular subtypes of breast cancer. Breast 2015, 24 (Suppl. S2), S26-S35. [CrossRef]

2. Baselga, J.; Campone, M.; Piccart-Gebhart, M.; Burris, H.A.; Rugo, H.S.; Sahmoud, T.; Noguchi, S.; Gnant, M.; Pritchard, K.I.; Lebrun, F.; et al. Everolimus in postmenopausal hormone-receptor-positive advanced breast cancer. N. Engl. J. Med. 2012, 366, 520-529. [CrossRef]

3. Finn, R.S.; Martin, M.; Rugo, H.S.; Jones, S.; Im, S.-A.; Gelmon, K.; Harbeck, N.; Lipatov, O.N.; Walshe, J.M.; Moulder, S.; et al. Palbociclib and letrozole in advanced breast cancer. N. Engl. J. Med. 2016, 375, 1925-1936. [CrossRef]

4. Cristofanilli, M.; Turner, N.C.; Bondarenko, I.; Ro, J.; Im, S.-A.; Masuda, N.; Colleoni, M.; DeMichele, A.; Loi, S.; Verma, S.; et al. Fulvestrant plus palbociclib versus fulvestrant plus placebo for treatment of hormone-receptor-positive, HER2-negative metastatic breast cancer that progressed on previous endocrine therapy (PALOMA-3): Final analysis of the multicentre, double-blind, phase 3 randomised controlled trial. Lancet Oncol. 2016, 17, 425-439. [CrossRef]

5. Goetz, M.P.; Toi, M.; Campone, M.; Sohn, J.; Paluch-Shimon, S.; Huober, J.; Park, I.H.; Trédan, O.; Chen, S.-C.; Manso, L.; et al. MONARCH 3: Abemaciclib as initial therapy for advanced breast cancer. J. Clin. Oncol. 2017, 35, 3638-3646. [CrossRef]

6. Sledge, G.W., Jr.; Toi, M.; Neven, P.; Sohn, J.; Inoue, K.; Pivot, X.; Burdaeva, O.; Okera, M.; Masuda, N.; Kaufman, P.A.; et al. MONARCH 2: Abemaciclib in combination with fulvestrant in women with HR+/HER2 - advanced breast cancer who had progressed while receiving endocrine therapy. J. Clin. Oncol. 2017, 35, 2875-2884. [CrossRef]

7. Hortobagyi, G.N.; Stemmer, S.M.; Burris, H.A.; Yap, Y.S.; Sonke, G.S.; Paluch-Shimon, S.; Campone, M.; Blackwell, K.L.; André, F.; Winer, E.P.; et al. Ribociclib as first-line therapy for HR-positive, advanced breast cancer. N. Engl. J. Med. 2016, 375, 1738-1748. [CrossRef] [PubMed]

8. Slamon, D.J.; Neven, P.; Chia, S.; Fasching, P.A.; De Laurentiis, M.; Im, S.-A.; Petrakova, K.; Bianchi, G.V.; Esteva, F.J.; Martín, M.; et al. Phase III randomized study of Ribociclib and fulvestrant in hormone receptor-positive, human epidermal growth factor receptor 2-negative advanced breast cancer: MONALEESA-3. J. Clin. Oncol. 2018, 36, 2465-2472. [CrossRef] [PubMed] 
9. André, F.; Ciruelos, E.; Rubovszky, G.; Campone, M.; Loibl, S.; Rugo, H.S.; Iwata, H.; Conte, P.; Mayer, I.A.; Kaufman, B.; et al. Alpelisib for PIK3CA-mutated, hormone receptor-positive advanced breast cancer. N. Engl. J. Med. 2019, 380, 1929-1940. [CrossRef] [PubMed]

10. Tripathy, D.; Im, S.-A.; Colleoni, M.; Franke, F.; Bardia, A.; Harbeck, N.; Hurvitz, S.A.; Chow, L.; Sohn, J.; Lee, K.S.; et al. Ribociclib plus endocrine therapy for premenopausal women with hormone-receptor-positive, advanced breast cancer (MONALEESA-7): A randomised phase 3 trial. Lancet Oncol. 2018, 19, 904-915. [CrossRef]

11. Schettini, F.; Giudici, F.; Giuliano, M.; Cristofanilli, M.; Arpino, G.; Del Mastro, L.; Puglisi, F.; De Placido, S.; Paris, I.; De Placido, P.; et al. Overall survival of CDK4/6-inhibitor-based treatments in clinically relevant subgroups of metastatic breast cancer: Systematic review and meta-analysis. J. Natl. Cancer Inst. 2020, 112, 1089-1097. [CrossRef] [PubMed]

12. Gradishar, W. Taxanes for the treatment of metastatic breast cancer. Breast Cancer Basic Clin. Res. 2012, 6, 159-171. [CrossRef]

13. Twelves, C.C.; Cortes, J.; Vahdat, L.L.; Olivo, M.M.; He, Y.Y.; Kaufman, P.P.; Awada, A. Efficacy of eribulin in women with metastatic breast cancer: A pooled analysis of two phase 3 studies. Breast Cancer Res. Treat. 2014, 148, 553-561. [CrossRef] [PubMed]

14. National Cancer Institute. Surveillance, Epidemiology, and End Results (SEER) Program. SEER Statistics for Breast Cancer. Available online: https:/ / seer.cancer.gov/statfacts/html/breast.html (accessed on 9 January 2020).

15. Caswell-Jin, J.L.; Plevritis, S.K.; Tian, L.; Cadham, C.J.; Xu, C.; Stout, N.K.; Sledge, G.W.; Mandelblatt, J.S.; Kurian, A.W. Change in survival in metastatic breast cancer with treatment advances: Meta-analysis and systematic review. JNCI Cancer Spectr. 2018, 2, pky062. [CrossRef] [PubMed]

16. Rugo, H.S.; Rumble, R.B.; Macrae, E.; Barton, D.L.; Connolly, H.K.; Dickler, M.N.; Fallowfield, L.; Fowble, B.; Ingle, J.N.; Jahanzeb, M.; et al. Endocrine therapy for hormone receptor-positive metastatic breast cancer: American society of clinical oncology guideline. J. Clin. Oncol. 2016, 34, 3069-3103. [CrossRef] [PubMed]

17. National Comprehensive Cancer Network. NCCN Guidelines for Breast Cancer. Version 6.2020. Available online: https: //www.nccn.org/professionals/physician_gls/pdf/breast.pdf (accessed on 10 September 2020).

18. Cardoso, F.; Paluch-Shimon, S.; Senkus, E.; Curigliano, G.; Aapro, M.; André, F.; Barrios, C.; Bergh, J.; Bhattacharyya, G.; Biganzoli, L.; et al. 5th ESO-ESMO international consensus guidelines for advanced breast cancer (ABC 5). Ann. Oncol. 2020, 31, 1623-1649. [CrossRef]

19. Giuliano, M.; Schettini, F.; Rognoni, C.; Milani, M.; Jerusalem, G.; Bachelot, T.; De Laurentiis, M.; Thomas, G.; De Placido, P.; Arpino, G.; et al. Endocrine treatment versus chemotherapy in postmenopausal women with hormone receptor-positive, HER2-negative, metastatic breast cancer: A systematic review and network meta-analysis. Lancet Oncol. 2019, 20, 1360-1369. [CrossRef]

20. Wilson, F.R.; Varu, A.; Mitra, D.; Cameron, C.; Iyer, S. Systematic review and network meta-analysis comparing Palbociclib with chemotherapy agents for the treatment of postmenopausal women with HR-positive and HER2-negative advanced/metastatic breast cancer. Breast Cancer Res. Treat. 2017, 166, 167-177. [CrossRef]

21. Generali, D.; Venturini, S.; Rognoni, C.; Ciani, O.; Pusztai, L.; Loi, S.; Jerusalem, G.; Bottini, A.; Tarricone, R. A network metaanalysis of everolimus plus exemestane versus chemotherapy in the first- and second-line treatment of estrogen receptor-positive metastatic breast cancer. Breast Cancer Res. Treat. 2015, 152, 95-117. [CrossRef]

22. Brandão, M.; Maurer, C.; Ziegelmann, P.K.; Pondé, N.F.; Ferreira, A.; Martel, S.; Piccart, M.; De Azambuja, E.; De Biasi, M.; Lambertini, M. Endocrine therapy-based treatments in hormone receptor-positive/HER2-negative advanced breast cancer: Systematic review and network meta-analysis. ESMO Open 2020, 5, e000842. [CrossRef]

23. DerSimonian, R.; Laird, N. Meta-analysis in clinical trials. Control Clin. Trials 1986, 7, 177-188. [CrossRef]

24. Higgins, J.P.T.; Thompson, S.G. Quantifying heterogeneity in a meta-analysis. Stat. Med. 2002, 21, 1539-1558. [CrossRef] [PubMed]

25. Sterne, J.A.; Egger, M. Funnel plots for detecting bias in meta-analysis: Guidelines on choice of axis. J. Clin. Epidemiol. 2001, 54, 1046-1055. [CrossRef]

26. Bachelot, T.; Bourgier, C.; Cropet, C.; Ray-Coquard, I.; Ferrero, J.-M.; Freyer, G.; Abadie-Lacourtoisie, S.; Eymard, J.-C.; Debled, M.; Spaëth, D.; et al. Randomized phase II trial of everolimus in combination with tamoxifen in patients with hormone receptorpositive, human epidermal growth factor receptor 2-negative metastatic breast cancer with prior exposure to aromatase inhibitors: A GINECO Study. J. Clin. Oncol. 2012, 30, 2718-2724. [CrossRef]

27. Baselga, J.; Im, S.A.S.; Iwata, H.; Cortés, J.; De Laurentiis, M.; Jiang, Z.; Arteaga, C.C.; Jonat, W.; Clemons, M.J.; Ito, Y.Y.; et al. Buparlisib plus fulvestrant versus placebo plus fulvestrant in postmenopausal, hormone receptor-positive, HER2-negative, advanced breast cancer (BELLE-2): A randomised, double-blind, placebo-controlled, phase 3 trial. Lancet Oncol. 2017, 18, 904-916. [CrossRef]

28. Bonneterre, J.; Thürlimann, B.; Robertson, J.R.; Krzakowski, M.; Mauriac, L.; Koralewski, P.; Vergote, I.; Webster, A.; Steinberg, M.; Von Euler, M. Anastrozole versus tamoxifen as first-line therapy for advanced breast cancer in 668 postmenopausal women: Results of the tamoxifen or arimidex randomized group efficacy and tolerability study. J. Clin. Oncol. 2000, 18, $3748-3757$. [CrossRef]

29. Buzdar, A.; Douma, J.; Davidson, N.; Elledge, R.; Morgan, M.; Smith, R.; Porter, L.; Nabholtz, J.; Xiang, X.; Brady, C. Phase III, multicenter, double-blind, randomized study of letrozole, an aromatase inhibitor, for advanced breast cancer versus megestrol acetate. J. Clin. Oncol. 2001, 19, 3357-3366. [CrossRef] [PubMed] 
30. Chia, S.; Gradishar, W.J.; Mauriac, L.; Bines, J.; Amant, F.; Federico, M.; Fein, L.; Romieu, G.; Buzdar, A.; Robertson, J.F.; et al. Double-blind, randomized placebo controlled trial of fulvestrant compared with exemestane after prior nonsteroidal aromatase inhibitor therapy in postmenopausal women with hormone receptor-positive, advanced breast cancer: Results from EFECT. J. Clin. Oncol. 2008, 26, 1664-1670. [CrossRef]

31. Di Leo, A.; Johnston, S.; Lee, K.S.; Ciruelos, E.; Lønning, P.E.; Janni, W.; O’Regan, R.; Mouret-Reynier, M.-A.; Kalev, D.; Egle, D.; et al. Buparlisib plus fulvestrant in postmenopausal women with hormone-receptor-positive, HER2-negative, advanced breast cancer progressing on or after mTOR inhibition (BELLE-3): A randomised, double-blind, placebo-controlled, phase 3 trial. Lancet Oncol. 2018, 19, 87-100. [CrossRef]

32. Di Leo, A.; Jerusalem, G.; Petruzelka, L.; Torres, R.; Bondarenko, I.N.; Khasanov, R.; Verhoeven, D.; Pedrini, J.L.; Smirnova, I.; Lichinitser, M.R.; et al. Results of the CONFIRM phase III trial comparing fulvestrant $250 \mathrm{mg}$ with fulvestrant $500 \mathrm{mg}$ in postmenopausal women with estrogen receptor-positive advanced breast cancer. J. Clin. Oncol. 2010, 28, 4594-4600. [CrossRef]

33. Finn, R.S.; Crown, J.P.; Lang, I.; Boér, K.; Bondarenko, I.M.; Kulyk, S.O.; Ettl, J.; Patel, R.; Pinter, T.; Schmidt, M.; et al. The cyclin-dependent kinase $4 / 6$ inhibitor palbociclib in combination with letrozole versus letrozole alone as first-line treatment of oestrogen receptor-positive, HER2-negative, advanced breast cancer (PALOMA-1/TRIO-18): A randomised phase 2 study. Lancet Oncol. 2015, 16, 25-35. [CrossRef]

34. Howell, A.; Robertson, J.F.; Abram, P.; Lichinitser, M.R.; Elledge, R.; Bajetta, E.; Watanabe, T.; Morris, C.; Webster, A.; Dimery, I.; et al. Comparison of Fulvestrant Versus Tamoxifen for the Treatment of Advanced Breast Cancer in Postmenopausal Women Previously Untreated with Endocrine Therapy: A Multinational, Double-Blind, Randomized Trial. J. Clin. Oncol. 2004, 22, 1605-1613. [CrossRef]

35. Howell, A.; Robertson, J.; Quaresma Albano, J.; Aschermannova, A.; Mauriac, L.; Kleeberg, U.; Vergote, I.; Erikstein, B.; Webster, A.; Morris, C. Fulvestrant, formerly ICI 182,780, is as effective as anastrozole in postmenopausal women with advanced breast cancer progressing after prior endocrine treatment. J. Clin. Oncol. 2002, 20, 3396-3403. [CrossRef] [PubMed]

36. Johnston, S.R.; Kilburn, L.S.; Ellis, P.; Dodwell, D.; Cameron, D.; Hayward, L.; Im, Y.-H.; Braybrooke, J.P.; Brunt, A.M.; Cheung, K.-L.; et al. Fulvestrant plus anastrozole or placebo versus exemestane alone after progression on non-steroidal aromatase inhibitors in postmenopausal patients with hormone-receptor-positive locally advanced or metastatic breast cancer (SoFEA): A composite, multicentre, phase 3 randomised trial. Lancet Oncol. 2013, 14, 989-998. [CrossRef] [PubMed]

37. Jones, R.H.; Carucci, M.; Casbard, A.C.; Butler, R.; Alchami, F.; Bale, C.J.; Bezecny, P.; Joffe, J.; Moon, S.; Twelves, C.; et al. Capivasertib (AZD5363) plus fulvestrant versus placebo plus fulvestrant after relapse or progression on an aromatase inhibitor in metastatic ER-positive breast cancer (FAKTION): A randomized, double-blind, placebo-controlled, phase II trial. J. Clin. Oncol. 2019, 37, 1005. [CrossRef]

38. Kim, J.-Y.; Im, S.-A.; Jung, K.H.; Ro, J.; Sohn, J.; Kim, J.H.; Park, Y.H.; Kim, T.-Y.; Kim, S.-B.; Lee, K.S.; et al. Fulvestrant plus goserelin versus anastrozole plus goserelin versus goserelin alone for hormone receptor-positive, HER2-negative tamoxifenpretreated premenopausal women with recurrent or metastatic breast cancer (KCSG BR10-04): A multicentre, open-label, three-arm, randomised phase II trial (FLAG study). Eur. J. Cancer 2018, 103, 127-136. [CrossRef] [PubMed]

39. Kornblum, N.; Zhao, F.; Manola, J.; Klein, P.; Ramaswamy, B.; Brufsky, A.; Stella, P.J.; Burnette, B.; Telli, M.; Makower, D.F.; et al. Randomized phase II Trial of Fulvestrant plus everolimus or placebo in postmenopausal women with hormone receptor-positive, human epidermal growth factor receptor 2-negative metastatic breast cancer resistant to aromatase inhibitor therapy: Results of PrE0102. J. Clin. Oncol. 2018, 36, 1556-1563. [CrossRef] [PubMed]

40. Krop, E.I.E.; Mayer, I.I.; Ganju, V.V.; Dickler, M.M.; Johnston, S.; Morales, S.S.; Yardley, D.D.; Melichar, B.B.; Forero-Torres, A.A.; Lee, S.C.S.; et al. Pictilisib for oestrogen receptor-positive, aromatase inhibitor-resistant, advanced or metastatic breast cancer (FERGI): A randomised, double-blind, placebo-controlled, phase 2 trial. Lancet Oncol. 2016, 17, 811-821. [CrossRef]

41. Mehta, R.S.; Barlow, W.E.; Albain, K.S.; Vandenberg, T.A.; Dakhil, S.R.; Tirumali, N.R.; Lew, D.L.; Hayes, D.F.; Gralow, J.R.; Livingston, R.B.; et al. Combination anastrozole and fulvestrant in metastatic breast cancer. N. Engl. J. Med. 2012, 367, 435-444. [CrossRef]

42. Milla-Santos, A.; Milla, L.; Portella, J.; Rallo, L.; Pons, M.; Rodes, E.; Casanovas, J.; Puig-Gali, M. Anastrozole versus tamoxifen as first-line therapy in postmenopausal patients with hormone-dependent advanced breast cancer: A prospective, randomized, Phase III Study. Am. J. Clin. Oncol. 2003, 26, 317-322. [CrossRef]

43. Mouridsen, H.; Gershanovich, M.; Sun, Y.; Pérez-Carrión, R.; Boni, C.; Monnier, A.; Apffelstaedt, J.; Smith, R.; Sleeboom, H.P.; Jänicke, F.; et al. Superior efficacy of letrozole versus tamoxifen as first-line therapy for postmenopausal women with advanced breast cancer: Results of a phase III Study of the international letrozole breast cancer group. J. Clin. Oncol. 2001, 19, 2596-2606. [CrossRef]

44. Nabholtz, J.; Buzdar, A.; Pollak, M.; Harwin, W.; Burton, G.; Mangalik, A.; Steinberg, M.; Webster, A.; Von Euler, M. Anastrozole is superior to tamoxifen as first-line therapy for advanced breast cancer in postmenopausal women: Results of a North American multicenter randomized trial. J. Clin. Oncol. 2000, 18, 3758-3767. [CrossRef] [PubMed]

45. Osborne, C.; Pippen, J.; Jones, S.E.; Parker, L.; Ellis, M.J.C.; Come, S.E.; Gertler, S.Z.; May, J.; Burton, G.V.; Dimery, I.W.; et al. Double-blind, randomized trial comparing the efficacy and tolerability of fulvestrant versus anastrozole in postmenopausal women with advanced breast cancer progressing on prior endocrine therapy: Results of a North American trial. J. Clin. Oncol. 2002, 20, 3386-3395. [CrossRef] [PubMed] 
46. Paridaens, R.J.; Dirix, L.Y.; Beex, L.V.; Nooij, M.; Cameron, D.A.; Cufer, T.; Piccart-Gebhart, M.; Bogaerts, J.; Therasse, P. Phase III study comparing exemestane with tamoxifen as first-line hormonal treatment of metastatic breast cancer in postmenopausal women: The european organisation for research and treatment of cancer breast Cancer Cooperative Group. J. Clin. Oncol. 2008, 26, 4883-4890. [CrossRef]

47. Robertson, J.F.; Llombart-Cussac, A.; Rolski, J.; Feltl, D.; Dewar, J.; MacPherson, E.; Lindemann, J.; Ellis, M.J. Activity of fulvestrant $500 \mathrm{mg}$ versus anastrozole $1 \mathrm{mg}$ as first-line treatment for advanced breast cancer: Results from the FIRST Study. J. Clin. Oncol. 2009, 27, 4530-4535. [CrossRef] [PubMed]

48. Robertson, J.F.R.; Bondarenko, I.M.; Trishkina, E.; Dvorkin, M.; Panasci, L.; Manikhas, A.; Shparyk, Y.; Cardona-Huerta, S.; Cheung, K.-L.; Philco-Salas, M.J.; et al. Fulvestrant $500 \mathrm{mg}$ versus anastrozole $1 \mathrm{mg}$ for hormone receptor-positive advanced breast cancer (FALCON): An international, randomised, double-blind, phase 3 trial. Lancet 2016, 388, 2997-3005. [CrossRef]

49. Wolff, A.C.; Lazar, A.A.; Bondarenko, I.; Garin, A.M.; Brincat, S.; Chow, L.; Sun, Y.; Neskovic-Konstantinovic, Z.; Guimaraes, R.C.; Fumoleau, P.; et al. Randomized phase III placebo-controlled trial of letrozole plus oral temsirolimus as first-line endocrine therapy in postmenopausal women with locally advanced or metastatic breast cancer. J. Clin. Oncol. 2013, 31, 195-202. [CrossRef] [PubMed]

50. Xu, B.; Jiang, Z.; Shao, Z.; Wang, J.; Feng, J.; Song, S.; Chen, Z.; Gu, K.; Yu, S.; Zhang, Y.; et al. Fulvestrant 250 mg versus anastrozole for Chinese patients with advanced breast cancer: Results of a multicentre, double-blind, randomised phase III trial. Cancer Chemother. Pharmacol. 2011, 67, 223-230. [CrossRef]

51. Yardley, D.A.; Ismail-Khan, R.R.; Melichar, B.; Lichinitser, M.; Munster, P.N.; Klein, P.M.; Cruickshank, S.; Miller, K.D.; Lee, M.J.; Trepel, J.B. Randomized phase II, double-blind, placebo-controlled study of exemestane with or without entinostat in postmenopausal women with locally recurrent or metastatic estrogen receptor-positive breast cancer progressing on treatment with a nonsteroidal aromatase inhibitor. J. Clin. Oncol. 2013, 31, 2128-2135. [CrossRef]

52. Yardley, D.A.; Noguchi, S.S.; Pritchard, K.I.; Burris, H.H.; Baselga, J.; Gnant, M.; Hortobagyi, G.N.; Campone, M.; Pistilli, B.B.; Piccart-Gebhart, M.; et al. Everolimus plus exemestane in postmenopausal patients with HR+ breast cancer: BOLERO-2 final progression-free survival analysis. Adv. Ther. 2013, 30, 870-884. [CrossRef] [PubMed]

53. D'Souza, A.; Spicer, D.; Lu, J. Overcoming endocrine resistance in metastatic hormone receptor-positive breast cancer. J. Hematol. Oncol. 2018, 11, 80. [CrossRef]

54. Schettini, F.; Buono, G.; Trivedi, M.V.; De Placido, S.; Arpino, G.; Giuliano, M. PI3K/mTOR Inhibitors in the treatment of luminal breast cancer. why, when and to whom. Breast Care 2017, 12, 290-294. [CrossRef] [PubMed]

55. McCartney, A.; Migliaccio, I.; Bonechi, M.; Biagioni, C.; Romagnoli, D.; De Luca, F.; Galardi, F.; Risi, E.; De Santo, I.; Benelli, M.; et al. Mechanisms of resistance to CDK4/6 inhibitors: Potential implications and biomarkers for clinical practice. Front. Oncol. 2019, 9, 666. [CrossRef] [PubMed]

56. Chandarlapaty, S.; Chen, D.; He, W.; Sung, P.; Samoila, A.; You, D.; Bhatt, T.; Patel, P.; Voi, M.; Gnant, M.; et al. Prevalence of ESR1 mutations in cell-free DNA and outcomes in metastatic breast cancer: A secondary analysis of the BOLERO-2 Clinical Trial. JAMA Oncol. 2016, 2, 1310-1315. [CrossRef]

57. Connolly, R.M.; Zhao, F.; Miller, K.D.; Lee, M.-J.; Piekarz, R.L.; Smith, K.L.; Brown-Glaberman, U.; Winn, J.S.; Faller, B.A.; Onitilo, A.A.; et al. Abstract GS4-02: E2112: Randomized phase 3 trial of endocrine therapy plus entinostat/placebo in patients with hormone receptor-positive advanced breast cancer. A trial of the ECOG-ACRIN cancer research group. Gen. Sess. Abstr. 2020, 81, GS4-GS02.

58. Toss, A.; Venturelli, M.; Sperduti, I.; Molinaro, E.; Isca, C.; Barbieri, E.; Piacentini, F.; Omarini, C.; Cortesi, L.; Cascinu, S.; et al. First-line treatment for endocrine-sensitive bone-only metastatic breast cancer: Systematic review and meta-analysis. Clin. Breast Cancer 2019, 19, e701-e716. [CrossRef]

59. Lee, S.J.; Park, S.; Ahn, H.K.; Yi, J.H.; Cho, E.Y.; Sun, J.M.; Lee, J.E.; Nam, S.J.; Yang, J.-H.; Park, Y.H.; et al. Implications of bone-only metastases in breast cancer: Favorable preference with excellent outcomes of hormone receptor positive breast cancer. Cancer Res. Treat. 2011, 43, 89-95. [CrossRef]

60. Gao, J.J.; Cheng, J.; Bloomquist, E.; Sanchez, J.; Wedam, S.B.; Singh, H.; Amiri-Kordestani, L.; Ibrahim, A.; Sridhara, R.; Goldberg, K.B.; et al. CDK4/ 6 inhibitor treatment for patients with hormone receptor-positive, HER2-negative, advanced or metastatic breast cancer: A US Food and Drug Administration pooled analysis. Lancet Oncol. 2020, 21, 250-260. [CrossRef]

61. Rugo, H.S.; Lerebours, F.; Ciruelos, E.; Drullinsky, P.; Ruiz Borrego, M.; Neven, P.; Park, Y.H.; Prat, A.; Bachelot, T.; Juric, D.; et al. Alpelisib (ALP) + fulvestrant (FUL) in patients (pts) with PIK3CA-mutated (mut) hormone receptor-positive (HR+), human epidermal growth factor receptor 2-negative (HER2-) advanced breast cancer (ABC) previously treated with cyclin-dependent kinase 4/6 inhibitor (CDKi) + aromatase inhibitor (AI): BYLieve study results. J. Clin. Oncol. 2020, 38, 1006. [CrossRef]

62. Dent, S.; Cortés, J.; Im, Y.-H.; Diéras, V.; Harbeck, N.; Krop, I.; Wilson, T.; Cui, N.; Schimmoller, F.; Hsu, J.; et al. Phase III randomized study of taselisib or placebo with fulvestrant in estrogen receptor-positive, PIK3CA-mutant, HER2-negative, advanced breast cancer: The SANDPIPER trial. Ann. Oncol. 2021, 32, 197-207. [CrossRef]

63. Tudur Smith, C.; Clarke, M.; Marson, T.; Riley, S.; Tierney, J. A framework for deciding if individual participant data are likely to be worthwhile. In Proceedings of the Cochrane Colloquium, Vienna, Austria, 3-7 October 2015.

64. Tierney, J.F.; Fisher, D.J.; Burdett, S.; Stewart, L.A.; Parmar, M.K.B. Comparison of aggregate and individual participant data approaches to meta-analysis of randomised trials: An observational study. PLoS Med. 2020, 17, e1003019. [CrossRef] 
65. Tang, J.-L.; Liu, J.L. Misleading funnel plot for detection of bias in meta-analysis. J. Clin. Epidemiol. 2000, 53, 477-484. [CrossRef]

66. Lau, J.; Ioannidis, J.P.A.; Terrin, N.; Schmid, C.H.; Olkin, I. The case of the misleading funnel plot. BMJ 2006, 333, 597-600. [CrossRef] [PubMed]

67. Higgins, J.P.T.; Green, S. Cochrane Handbook for Systematic Reviews of Interventions; Version 5.1.0; The Cochrane Collaboration: London, UK, 2011; Available online: https://training.cochrane.org/handbook/archive/v5.1/ (accessed on 10 September 2020).

68. Sterne, J.A.C.; Sutton, A.J.; Ioannidis, J.P.A.; Terrin, N.; Jones, D.R.; Lau, J.; Carpenter, J.; Rücker, G.; Harbord, R.M.; Schmid, C.H.; et al. Recommendations for examining and interpreting funnel plot asymmetry in meta-analyses of randomised controlled trials. BMJ 2011, 343, d4002. [CrossRef] [PubMed]

69. Lobbezoo, D.J.A.; Van Kampen, R.; Voogd, A.; Dercksen, M.; van den Berkmortel, F.; Smilde, T.; Van De Wouw, A.; Peters, F.; Van Riel, J.; Peters, N.; et al. In real life, one-quarter of patients with hormone receptor-positive metastatic breast cancer receive chemotherapy as initial palliative therapy: A study of the Southeast Netherlands Breast Cancer Consortium. Ann. Oncol. 2015, 27, 256-262. [CrossRef] [PubMed]

70. Cazzaniga, M.; Mustacchi, G.; Giordano, M.; Garrone, O.; Donadio, M.; Del Mastro, L.; Livi, L.; Natoli, C.; Michelotti, A.; Turletti, A.; et al. 259P adherence to International ESO-ESMO (ABC) guide-lines in HER2-ve metastatic breast cancer (MBC) patients (pts): Preliminary results of the GIM 13-AMBRA Study. Ann. Oncol. 2017, 28, v83-v84. [CrossRef]

71. André, F.; Neven, P.; Marinsek, N.; Zhang, J.; Baladi, J.-F.; Degun, R.; Benelli, G.; Saletan, S.; Jerusalem, G. Disease management patterns for postmenopausal women in Europe with hormone-receptor-positive, human epidermal growth factor receptor-2 negative advanced breast cancer. Curr. Med. Res. Opin. 2014, 30, 1007-1016. [CrossRef] [PubMed]

72. Bonotto, M.; Gerratana, L.; Di Maio, M.; De Angelis, C.; Cinausero, M.; Moroso, S.; Milano, M.; Stanzione, B.; Gargiulo, P.; Iacono, D.; et al. Chemotherapy versus endocrine therapy as first-line treatment in patients with luminal-like HER2-negative metastatic breast cancer: A propensity score analysis. Breast 2017, 31, 114-120. [CrossRef]

73. Turner, N.C.; Slamon, D.J.; Ro, J.; Bondarenko, I.; Im, S.-A.; Masuda, N.; Colleoni, M.; DeMichele, A.; Loi, S.; Verma, S.; et al. Overall Survival with Palbociclib and Fulvestrant in Advanced Breast Cancer. N. Engl. J. Med. 2018, 379, 1926-1936. [CrossRef]

74. Slamon, D.J.; Neven, P.; Chia, S.; Fasching, P.A.; De Laurentiis, M.; Im, S.-A.; Petrakova, K.; Bianchi, G.V.; Esteva, F.J.; Martín, M.; et al. Overall Survival with Ribociclib plus Fulvestrant in Advanced Breast Cancer. N. Engl. J. Med. 2020, 382, 514-524. [CrossRef]

75. Im, S.-A.; Lu, Y.-S.; Bardia, A.; Harbeck, N.; Colleoni, M.; Franke, F.; Chow, L.; Sohn, J.; Lee, K.-S.; Campos-Gomez, S.; et al. Overall Survival with Ribociclib plus Endocrine Therapy in Breast Cancer. N. Engl. J. Med. 2019, 381, 307-316. [CrossRef] [PubMed]

76. Bergh, J.; Jonsson, P.-E.; Lidbrink, E.K.; Trudeau, M.; Eiermann, W.; Brattström, D.; Lindemann, J.P.; Wiklund, F.; Henriksson, R. FACT: An Open-Label Randomized Phase III Study of Fulvestrant and Anastrozole in Combination Compared With Anastrozole Alone As First-Line Therapy for Patients With Receptor-Positive Postmenopausal Breast Cancer. J. Clin. Oncol. 2012, 30, 1919-1925. [CrossRef] [PubMed]

77. Di Leo, A.; Jerusalem, G.; Petruzelka, L.; Torres, R.; Bondarenko, I.N.; Khasanov, R.; Verhoeven, D.; Pedrini, J.L.; Smirnova, I.; Lichinitser, M.R.; et al. Final Overall Survival: Fulvestrant $500 \mathrm{mg}$ vs $250 \mathrm{mg}$ in the Randomized CONFIRM Trial. J. Natl. Cancer Inst. 2014, 106, djt337. [CrossRef] [PubMed]

78. Ellis, M.J.; Llombart-Cussac, A.; Feltl, D.; Dewar, J.A.; Jasiówka, M.; Hewson, N.; Rukazenkov, Y.; Robertson, J.F. Fulvestrant $500 \mathrm{mg}$ Versus Anastrozole $1 \mathrm{mg}$ for the First-Line Treatment of Advanced Breast Cancer: Overall Survival Analysis From the Phase II FIRST Study. J. Clin. Oncol. 2015, 33, 3781-3787. [CrossRef]

79. Iwata, H.; Masuda, N.; Ohno, S.; Rai, Y.; Sato, Y.; Ohsumi, S.; Hashigaki, S.; Nishizawa, Y.; Hiraoka, M.; Morimoto, T.; et al. A randomized, double-blind, controlled study of exemestane versus anastrozole for the first-line treatment of postmenopausal Japanese women with hormone-receptor-positive advanced breast cancer. Breast Cancer Res. Treat. 2013, 139, 441-451. [CrossRef] [PubMed]

80. Kaufmann, M.; Bajetta, E.; Dirix, L.Y.; Fein, L.E.; Jones, S.E.; Zilembo, N.; Dugardyn, J.-L.; Nasurdi, C.; Mennel, R.G.; Cervek, J.; et al. Exemestane Is Superior to Megestrol Acetate After Tamoxifen Failure in Postmenopausal Women With Advanced Breast Cancer: Results of a Phase III Randomized Double-Blind Trial. J. Clin. Oncol. 2000, 18, 1399-1411. [CrossRef] [PubMed]

81. Klijn, J.G.M.; Beex, L.V.A.M.; Mauriac, L.; Van Zijl, J.A.; Veyret, C.; Wildiers, J.; Jassem, J.; Piccart, M.; Burghouts, J.; Becquart, D.; et al. Combined Treatment With Buserelin and Tamoxifen in Premenopausal Metastatic Breast Cancer: A Randomized Study. J. Natl. Cancer Inst. 2000, 92, 903-911. [CrossRef]

82. Llombart-Cussac, A.; Cortés, J.; Paré, L.; Galván, P.; Bermejo, B.; Martínez, N.; Vidal, M.; Pernas, S.; López, R.; Muñoz, M.; et al. HER2-enriched subtype as a predictor of pathological complete response following trastuzumab and lapatinib without chemotherapy in early-stage HER2-positive breast cancer (PAMELA): An open-label, single-group, multicentre, phase 2 trial. Lancet Oncol. 2017, 18, 545-554. [CrossRef]

83. Robertson, J.F.R.; Lindemann, J.P.O.; Llombart-Cussac, A.; Rolski, J.; Feltl, D.; Dewar, J.; Emerson, L.; Dean, A.; Ellis, M.J. Fulvestrant $500 \mathrm{mg}$ versus anastrozole $1 \mathrm{mg}$ for the first-line treatment of advanced breast cancer: Follow-up analysis from the randomized 'FIRST' study. Breast Cancer Res. Treat. 2012, 136, 503-511. [CrossRef] 
84. Rose, C.; Vtoraya, O.; Pluzanska, A.; Davidson, N.; Gershanovich, M.; Thomas, R.; Johnson, S.; Caicedo, J.; Gervasio, H.; Manikhas, G.; et al. An open randomised trial of second-line endocrine therapy in advanced breast cancer. Eur. J. Cancer 2003, 39, 2318-2327. [CrossRef]

85. Sledge, G.W.; Toi, M.; Neven, P.; Sohn, J.; Inoue, K.; Pivot, X.; Burdaeva, O.; Okera, M.; Masuda, N.; Kaufman, P.A.; et al. The Effect of Abemaciclib Plus Fulvestrant on Overall Survival in Hormone Receptor-Positive, ERBB2-Negative Breast Cancer That Progressed on Endocrine Therapy-MONARCH 2. JAMA Oncol. 2020, 6, 116-124. [CrossRef] [PubMed] 